\title{
Overview of VOC emissions and chemistry from PTR-TOF-MS measurements during the SusKat-ABC campaign: high acetaldehyde, isoprene and isocyanic acid in wintertime air of the Kathmandu Valley
}

\author{
Chinmoy Sarkar ${ }^{1}$, $\operatorname{Vinayak}_{\text {Sinha }}{ }^{1}$, Vinod Kumar ${ }^{1}$, Maheswar Rupakheti $^{2,3}$, Arnico Panday $^{4}$, Khadak S. Mahata $^{2}$, \\ Dipesh Rupakheti ${ }^{5}$, Bhogendra Kathayat ${ }^{3}$, and Mark G. Lawrence ${ }^{2}$ \\ ${ }^{1}$ Department of Earth and Environmental Sciences, Indian Institute of Science Education and Research Mohali, Sector 81, S. \\ A. S. Nagar, Manauli PO, Punjab, 140306, India \\ ${ }^{2}$ Institute for Advanced Sustainability Studies (IASS), Berliner Str. 130, 14467 Potsdam, Germany \\ ${ }^{3}$ Himalayan Sustainability Institute (HIMSI), Kathmandu, Nepal \\ ${ }^{4}$ International Centre for Integrated Mountain Development (ICIMOD), Khumaltar, Lalitpur, Nepal \\ ${ }^{5}$ Key Laboratory of Tibetan Environment Changes and Land Surface Processes, Institute of Tibetan Plateau Research, \\ Chinese Academy of Sciences, Beijing, 100101, China \\ Correspondence to: Vinayak Sinha (vsinha@iisermohali.ac.in)
}

Received: 10 August 2015 - Published in Atmos. Chem. Phys. Discuss.: 15 September 2015

Revised: 19 February 2016 - Accepted: 8 March 2016 - Published: 24 March 2016

\begin{abstract}
The Kathmandu Valley in Nepal suffers from severe wintertime air pollution. Volatile organic compounds (VOCs) are key constituents of air pollution, though their specific role in the valley is poorly understood due to insufficient data. During the SusKat-ABC (Sustainable Atmosphere for the Kathmandu Valley-Atmospheric Brown Clouds) field campaign conducted in Nepal in the winter of 2012-2013, a comprehensive study was carried out to characterise the chemical composition of ambient Kathmandu air, including the determination of speciated VOCs, by deploying a proton transfer reaction time-of-flight mass spectrometer (PTR-TOF-MS) - the first such deployment in South Asia. In the study, 71 ion peaks (for which measured ambient concentrations exceeded the $2 \sigma$ detection limit) were detected in the PTR-TOF-MS mass scan data, highlighting the chemical complexity of ambient air in the valley. Of the 71 species, 37 were found to have campaign average concentrations greater than $200 \mathrm{ppt}$ and were identified based on their spectral characteristics, ambient diel profiles and correlation with specific emission tracers as a result of the high mass resolution $(m / \Delta m>4200)$ and temporal resolution ( $1 \mathrm{~min}$ ) of the PTR-TOF-MS. The concentration ranking in the average VOC mixing ratios dur-
\end{abstract}

ing our wintertime deployment was acetaldehyde $(8.8 \mathrm{ppb})$ $>$ methanol $(7.4 \mathrm{ppb})>$ acetone + propanal $(4.2 \mathrm{ppb})>$ benzene $(2.7 \mathrm{ppb})>$ toluene $(1.5 \mathrm{ppb})>$ isoprene $(1.1 \mathrm{ppb})$ $>$ acetonitrile $(1.1 \mathrm{ppb})>\mathrm{C} 8$-aromatics $(\sim 1 \mathrm{ppb})>$ furan $(\sim 0.5 \mathrm{ppb})>\mathrm{C} 9$-aromatics $(0.4 \mathrm{ppb})$. Distinct diel profiles were observed for the nominal isobaric compounds isoprene $(m / z=69.070)$ and furan $(m / z=69.033)$. Comparison with wintertime measurements from several locations elsewhere in the world showed mixing ratios of acetaldehyde $(\sim 9 \mathrm{ppb})$, acetonitrile $(\sim 1 \mathrm{ppb})$ and isoprene $(\sim 1 \mathrm{ppb})$ to be among the highest reported to date. Two "new" ambient compounds, namely formamide $(\mathrm{m} / \mathrm{z}=46.029)$ and acetamide ( $m / z=60.051)$, which can photochemically produce isocyanic acid in the atmosphere, are reported in this study along with nitromethane (a tracer for diesel exhaust), which has only recently been detected in ambient studies. Two distinct periods were selected during the campaign for detailed analysis: the first was associated with high wintertime emissions of biogenic isoprene and the second with elevated levels of ambient acetonitrile, benzene and isocyanic acid from biomass burning activities. Emissions from biomass burning and biomass co-fired brick kilns were found to be the dominant sources for compounds such 
as propyne, propene, benzene and propanenitrile, which correlated strongly with acetonitrile $\left(r^{2}>0.7\right)$, a chemical tracer for biomass burning. The calculated total $\mathrm{VOC} \mathrm{OH}$ reactivity was dominated by acetaldehyde $(24.0 \%)$, isoprene $(20.2 \%)$ and propene $(18.7 \%)$, while oxygenated VOCs and isoprene collectively contributed to more than $68 \%$ of the total ozone production potential. Based on known secondary organic aerosol (SOA) yields and measured ambient concentrations in the Kathmandu Valley, the relative SOA production potential of VOCs were benzene $>$ naphthalene $>$ toluene $>$ xylenes $>$ monoterpenes $>$ trimethylbenzenes $>$ styrene $>$ isoprene. The first ambient measurements from any site in South Asia of compounds with significant health effects such as isocyanic acid, formamide, acetamide, naphthalene and nitromethane have been reported in this study. Our results suggest that mitigation of intense wintertime biomass burning activities, in particular point sources such biomass co-fired brick kilns, would be important to reduce the emission and formation of toxic VOCs (such as benzene and isocyanic acid) in the Kathmandu Valley.

\section{Introduction}

The Kathmandu Valley is a bowl-shaped basin at an altitude of $\sim 1300 \mathrm{~m}$ that is surrounded by the Shivapuri, Phulchowki, Nagarjun and Chandragiri mountains, which have an altitude range of $2000-2800 \mathrm{~m}$ above mean sea level, (a.m.s.l.) and is prone to poor air quality and air pollution episodes (Panday et al., 2009). In particular during the winter mornings, due to the combination of suppressed mixing, katabatic wind flows and the topography of the basin, pollutants remain trapped under an inversion layer close to the surface of the valley (Kitada et al., 2003; Regmi et al., 2003). Previous studies in similar valley sites such as Santiago de Chile and Mexico City have investigated the coupling of topography, meteorology, atmospheric dynamics, emissions and chemical processes in exacerbating air pollution episodes and suggested ways to mitigate the air pollution and improve air quality (Molina et al., 2007; de Foy et al., 2006; Schmitz, 2005; Rappenglück et al., 2005). In contrast, only few such studies have been carried out within the Kathmandu Valley. Previous studies in the Kathmandu Valley have examined pollution in relation to carbon monoxide $(\mathrm{CO})$, nitrogen oxides $\left(\mathrm{NO}_{x}\right)$, sulfur dioxide $\left(\mathrm{SO}_{2}\right)$, ozone $\left(\mathrm{O}_{3}\right)$ (Panday and Prinn, 2009; Larssen et al., 1997; Yu et al., 2009; Ramana et al., 2004; Pudasainee et al., 2006) and particulate matter (Gurung and Bell, 2012; Sharma et al., 2012). An early study by Davidson et al. (1986) reported ambient average concentrations of 2 ppm CO during the winter season of 1982-1983. Offline measurements of nitrogen dioxide $\left(\mathrm{NO}_{2}\right)$ and sulfur dioxide $\left(\mathrm{SO}_{2}\right)$ performed by Larssen et al. (1997) examined the average pollution exposure in different regions of the val-
Table 1. Principal operational settings for PTR-TOF-MS parameters.

\begin{tabular}{ll}
\hline Parameter & Value \\
\hline Overall drift voltage $\left(U_{\text {drift }}\right)$ & $600 \mathrm{~V}$ \\
Temperature at drift tube $\left(T_{\text {drift }}\right)$ & $60{ }^{\circ} \mathrm{C}$ \\
Pressure at drift tube $\left(P_{\text {drift }}\right)$ & $2.2 \mathrm{mbar}$ \\
Length of the drift tube $\left(L_{\text {drift }}\right)$ & $9.3 \mathrm{~cm}$ \\
Reaction time $(t)$ & $92 \mu \mathrm{s}$ \\
Field strength of the drift tube $(E / N)^{*}$ & $135 \mathrm{Td}$ \\
\hline${ }^{*} E$ is the electric field strength $\left(\mathrm{V} \mathrm{cm}^{-1}\right)$ and $N$ is the gas number \\
density (molecule $\left.\mathrm{cm}^{-3}\right) .1 \mathrm{Td}=10^{-17} \mathrm{~V} \mathrm{~cm}^{2}$ molecule
\end{tabular}

ley and found that the brick kiln region south-east of the valley and cities were most severely affected. With regard to quantification of volatile organic compounds (VOCs) in downtown Kathmandu and a rural site in Nagarkot, data pertaining to light C2-C6 compounds were obtained in a study in November 1998 using 38 whole air samples analysed offline with a GC-FID (Sharma et al., 2000). Subsequently Yu et al. (2008) measured mixing ratios of seven monocyclic aromatic hydrocarbons, using long-path differential optical absorption spectroscopy (DOAS) at a suburban site in Kathmandu during January-February 2003. All these initial studies highlighted that traffic sources were major contributors to air pollution in the Kathmandu Valley (Yu et al., 2008). In the time since these studies, due to rapid urbanisation and population growth over the last decade, the wintertime air quality has deteriorated severely. However, very little information is currently available with regard to the emissions and chemistry of volatile organic compounds in the Kathmandu Valley. Except for a handful of species, most of which were measured only periodically using offline sampling methods, virtually no in situ data are available from the region with regard to the concentration and speciation of several important volatile organic compounds.

VOCs, in particular the reactive ones, have atmospheric lifetimes ranging from minutes to days (Atkinson, 2000) and exert a profound influence on regional air quality through their participation in chemical reactions leading to the formation of secondary pollutants such as tropospheric ozone and secondary organic aerosol (SOA). Both tropospheric ozone and secondary organic aerosol are important from the standpoint of air quality and climate due to their impact on health and the radiative forcing of the atmosphere (IPCC, 2013). Further, through reactions with the hydroxyl radicals (the detergent of the atmosphere; Lelieveld et al., 2004), photodissociation reactions and radical recycling reactions, VOCs strongly influence ambient $\mathrm{OH}$ reactivity and the budget of $\mathrm{HO}_{x}\left(\mathrm{OH}, \mathrm{HO}_{2}\right)$ radicals which control the removal rates of gaseous pollutants, including most greenhouse gases from the atmosphere. Inhalation of certain VOCs present in air also produces direct adverse health effects. For example ben- 


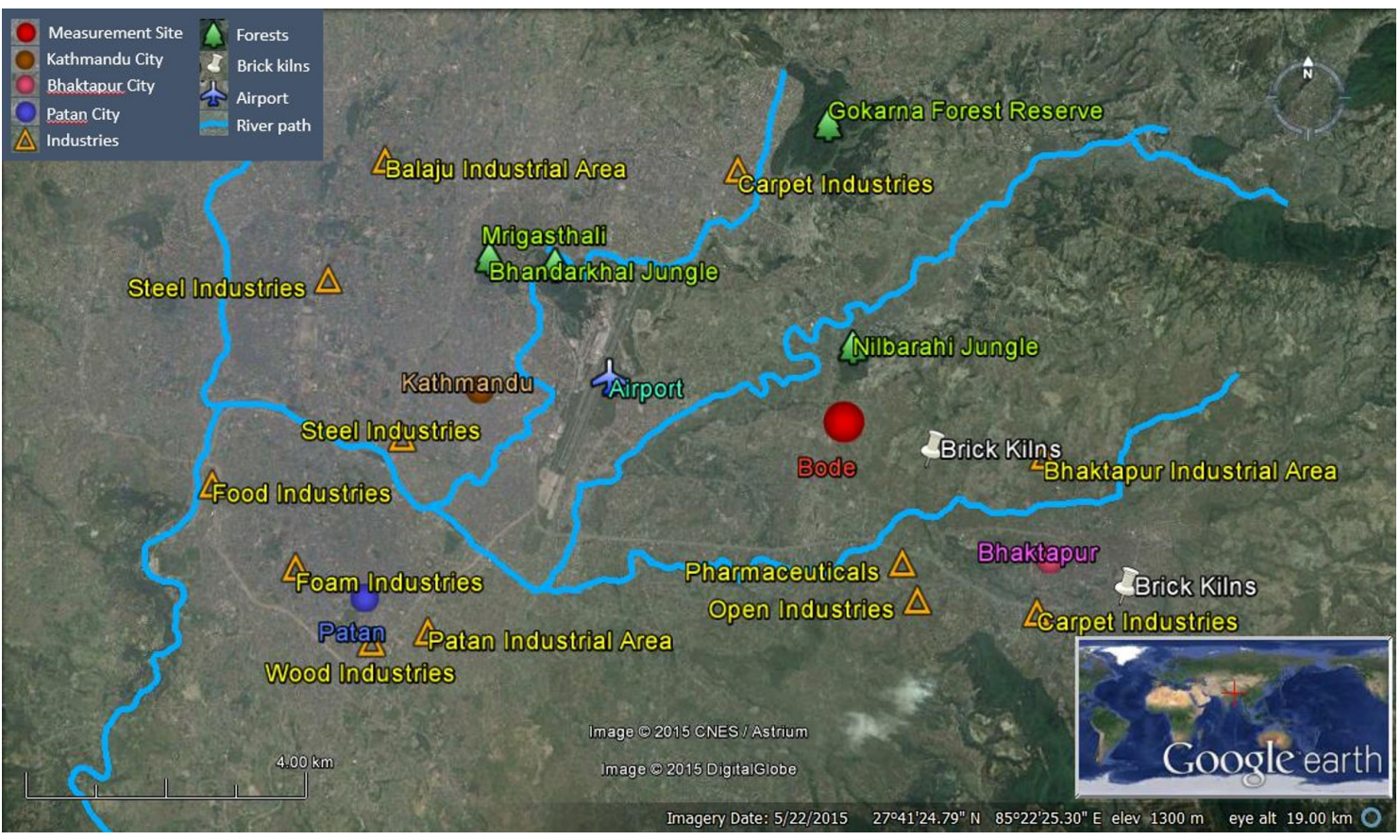

Figure 1. Location of the measurement site (Bode, red circle) along with surrounding cities (Kathmandu, brown circle; Patan, blue circle; Bhaktapur, pink circle), brick kilns (white markers), major industries (yellow triangles), forest areas (green tree symbols), airport (blue marker) and major river paths (sky blue) in the Google Earth image of the Kathmandu Valley (obtained on 22 May 2015 at 14:55 LT).

zene and nitromethane are reported to be human carcinogens by the World Health Organization (WHO, 2010).

In order to address gaps in our scientific understanding of the air pollution in the Kathmandu Valley, a large scale scientific experiment called the Sustainable Atmosphere for the Kathmandu Valley-Atmospheric Brown Clouds (SusKatABC) campaign was carried out in the winter of 2012-2013 by an international team of scientists. An overview of the campaign objectives, measurement suite and sites will be presented in an overview paper (Rupakheti et al., 2016) while the overview of meteorology and pollution transport processes will be presented in a second paper (Panday et al., 2016). Here we present results derived from the in situ measurements of speciated VOCs using a proton transfer reaction time-of-flight mass spectrometer (PTR-TOF-MS), the first such deployment in South Asia. Another version of this type of instrument, which has lower mass resolution, namely a proton transfer reaction quadrupole mass spectrometer (PTR-Q-MS), has been previously deployed in the northwestern Indo-Gangetic Plain in Mohali, India (Sarkar et al., 2013; Sinha et al., 2014).

With a mass resolving power $(m / \Delta m)$ of more than 4200 , PTR-TOF-MS measurements enable identification of several compounds based on their exact monoisotopic mass (molecular formula) and have fast time response ( $\sim 1 \mathrm{~min})$. These attributes were leveraged to quantify a suite of ambient VOCs at a suburban site (Bode: $27.689^{\circ} \mathrm{N}, 85.395^{\circ} \mathrm{E}$; 1345 ma.m.s.l.) in the Kathmandu Valley during December
2012-January 2013. Oxygenated VOCs such as methanol, acetaldehyde, sum of acetone and propanal, aromatic VOCs such as benzene, toluene, sum of C8-aromatics and sum of C9-aromatics, isoprene, furan and acetonitrile were quantified every minute and their diel emission profiles analysed to constrain major sources. Careful analysis of the ambient mass spectra from 21 to $210 \mathrm{Th}$ was undertaken to identify several "new" or rarely quantified VOCs based on their monoisotopic masses (and therefore molecular formula), spectral characteristics observed at a particular $m / z$ in a $0.005 \mathrm{amu}$ bin relative to the ion peak, ambient diel profiles and correlation with specific emission tracer molecules such as acetonitrile (a tracer for biomass burning). By contrasting periods in the chemical data set based on the dominance of biogenic emission sources and emissions from brick kilns co-fired with biomass respectively, VOCs emitted from brick kilns were constrained. The measured VOC concentrations in the Kathmandu Valley were compared with previous wintertime measurements from other urban/suburban sites and megacities. The diel profiles of rarely detected and measured VOCs such as nitromethane and isocyanic acid were correlated with tracer VOCs. The major VOC contributors to the total measured reactive carbon, the $\mathrm{VOC} \mathrm{OH}$ reactivity, ozone production potential and secondary organic aerosol formation potential were elucidated through detailed analyses. Finally, information pertaining to direct health impacts of some of the quantified VOCs detected in this complex 
chemical environment is discussed with conclusions and outlook for future VOC studies in the region.

\section{Experimental}

\subsection{Site description and prevalent meteorology}

The Kathmandu Valley is a bowl-shaped basin in the Himalayan foothills. The average altitude of the valley is $1300 \mathrm{~m}$ a.m.s.l. It is encircled by a ring of mountains that range from 2000 to $2800 \mathrm{~m}$ a.m.s.l., with about five mountain passes approximately 1500-1550 ma.m.s.l. (Panday et al., 2009). VOC measurements during this study were performed in the winter season from 19 December 2012 to 30 January 2013 at Bode $\left(27.689^{\circ} \mathrm{N}, 85.395^{\circ} \mathrm{E} ; 1345\right.$ ma.m.s.l.), which is a suburban site located in the westerly outflow of Kathmandu city.

Figure 1 shows a zoomed view of the land use in the vicinity of the measurement site (Bode, red circle; image derived using Google Earth on 22 May 2015 at 14:55 LT (local time)) in relation to the surrounding cities - Kathmandu $(\sim 10 \mathrm{~km}$ to the west; brown circle), Patan $(\sim 12 \mathrm{~km}$ south-west of the site; blue circle) and Bhaktapur ( $\sim 5 \mathrm{~km}$ south-east of the site; pink circle), major point sources and forested areas. Most of the agricultural fields near the site have unpaved tracks and were sold as small plots and are largely uncultivated. At some distance, there are agricultural fields on which rice is sown in the summer and either potatoes/vegetables or wheat is sown in winter. The major road (Bhaktapur road) is about $1 \mathrm{~km}$ south of the site. In 2011, the total populations of Kathmandu, Patan and Bhaktapur cities were 1003285 (population density: $20289 \mathrm{~km}^{-2}$ ), 226728 (population density: $14966 \mathrm{~km}^{-2}$ ) and 83658 (population density: $12753 \mathrm{~km}^{-2}$ ) respectively according to Central Bureau of Statistics (2011). The region east of the site was usually downwind but it is important to note that several brick kilns (white marker in Fig. 1; around 10 brick kilns) were located south-east of the site at about $1 \mathrm{~km}$ distance. Major industries (yellow triangles in Fig. 1) were concentrated primarily in the cities of Kathmandu (Balaju industrial area) and Patan (Patan industrial area), while Bhaktapur industrial area was located in the south-eastern direction within $2 \mathrm{~km}$ of the measurement site. About 20 small industries, mainly pharmaceuticals, plastic, tin, electronics and fabrics were located in this industrial area. Also a few plastic, electronics, wood, aluminium and iron industries were located within $3 \mathrm{~km}$ from the Bode site in the south-eastern direction. The Tribhuvan international airport was located west of the site ( $\sim 4 \mathrm{~km}$ from Bode).

The region north of the site has a small forested area (Nil Barahi jungle in Fig. 1; $\sim 0.5 \mathrm{~km}^{2}$ area) and a reserve forest (Gokarna reserve forest in Fig. $1 ; \sim 1.8 \mathrm{~km}^{2}$ area) at approximately 1.5 and $7 \mathrm{~km}$ from the measurement site respectively. Other nearby forest areas were located adjacent to the international airport (Mrigasthali and Bhandarkhal jungles;
$8-10 \mathrm{~km}$ from the site). The forests in the Kathmandu Valley consist of broad-leaved evergreen mixed forest of Schima castanopsis at the base (up to 1800 ma.m.s.l.), oak-laurel forest in the middle (1800 to 2400 ma.m.s.l.) and oak forest at the top, while the conifer tree species Pinus roxiburghii (Khote Salla) and Pinus wallichiana (Gobre Salla) are also found (Department of Plant Resources, Nepal, 2015). Other major tree species are Melia azedarach (Bakaino), Schima wallichii (Chilaune), Castanopsis indica (Dhale Katus), Piptanthus nepalensis (Suga Phul), Persea bombycina (Kaulo), Madhuca longifolia (Mauwa), Celtis australis (Khari), Quercus semecarpifolia (Khasru) and Cryptomeria japonica (Dhupi salla) (Department of Plant Resources, Nepal, 2015).

The general meteorological conditions within the Kathmandu Valley remain fairly similar throughout the winter season (Regmi et al., 2003; Panday et al., 2009) and it is worth mentioning that the winter of 2012-2013 was not anomalous. Conditions were calm during the mornings with shallow boundary layer and therefore what we see in the morning hours are emissions from the previous night and emissions from morning activities around the measurement site within a radius of few $\mathrm{km}$, rather than regional emissions. Cold pooling of air at night resulting in dilution of pollution was observed in the diel profiles of VOCs for period 1 when the 24/7 brick kilns were largely un-operational (for example between midnight and 05:00 LT). Shortly after sunrise, the surface air mixes in with air that was aloft. Finally during the afternoon (10:00-15:00 LT), westerly winds sweep the valley from west to east at wind speeds of $3-4 \mathrm{~m} \mathrm{~s}^{-1}$, advecting the emissions, some of which may get transported across the mountain passes (Kitada et al., 2003; Regmi et al., 2003; Panday et al., 2009).

Figure $2 \mathrm{~b}$ shows the box and whisker plots for the meteorological parameters measured at Bode from 16 to 30 January 2013 derived from the $1 \mathrm{~min}$ temporal resolution data acquired using meteorological sensors (Campbell Scientific Loughborough, UK) installed on the rooftop ( $\sim 25 \mathrm{~m}$ above ground and $\sim 5 \mathrm{~m}$ away from the instrument inlet). Daytime (08:00-17:00 LT) average ambient temperature for the measurement period was observed to be $12.2 \pm 4.5^{\circ} \mathrm{C}$. It is worth mentioning that most mornings were associated with dense fog (average ambient RH $>90 \%$ with visibility $<100 \mathrm{~m}$ ) whereas the afternoons were associated with highspeed westerly winds $\left(>4 \mathrm{~m} \mathrm{~s}^{-1}\right)$. Wind speeds from other wind sectors were generally lower (average wind speeds $\sim 1 \mathrm{~m} \mathrm{~s}^{-1}$ ). The early morning wind flow was normally from the south-eastern wind sector which comprised of several brick kilns and Bhaktapur city. Evening hours were also associated with dense fog and the relative humidity $(\mathrm{RH})$ was generally greater than $90 \%$ throughout the night. Minimum RH levels $(\sim 35 \%)$ were observed during midday. The sunrise typically occurred between 07:00 and 08:00 and sunset timings were around 17:00 Nepal standard time (NST). The range of atmospheric pressure during the campaign was 856$866 \mathrm{hPa}$. 

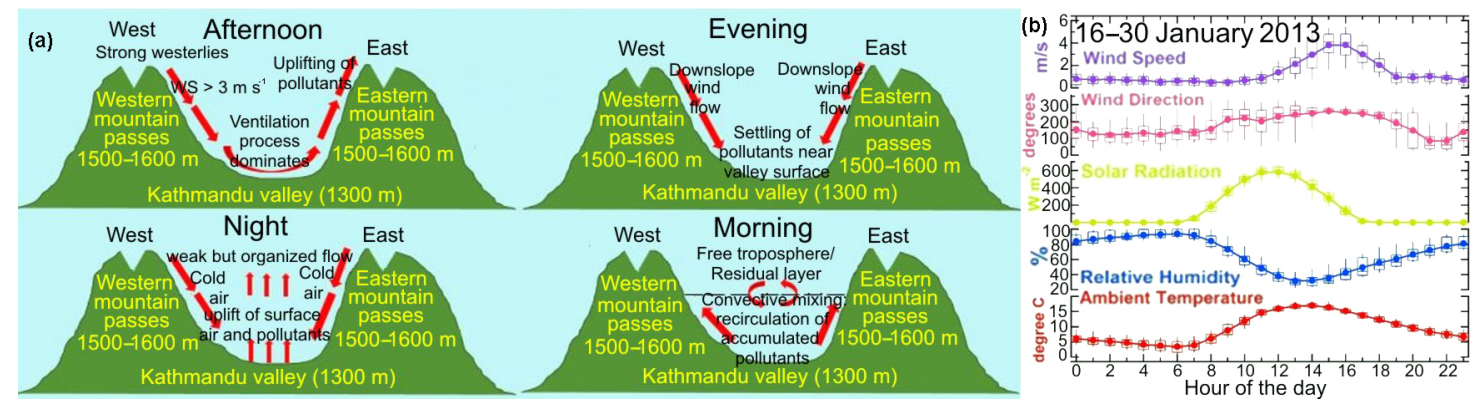

Figure 2. (a) Schematic of wind flow during different times of the day in the Kathmandu Valley. (b) Box and whisker plots of the measured meteorological parameters (wind speed, wind direction, solar radiation, relative humidity and ambient temperature) at the Bode site (1630 January 2013).

\subsection{VOC measurements using PTR-TOF-MS}

VOCs over the mass range $(21-210 \mathrm{amu})$ were measured using a commercial high-sensitivity PTR-TOF-MS (model 8000; Ionicon Analytic GmbH, Innsbruck, Austria). This instrument has been described in detail by Jordan et al. (2009) and is a more recent development of the PTR technique (Lindinger et al., 1998) that enables higher mass resolution at ppt level detection limit (Ruuskanen et al., 2011; Müller et al., 2010; Park et al., 2013; Stockwell et al., 2015). Briefly, the instrument consists of a hollow cathode ion source which produces a pure flow of the $\mathrm{H}_{3} \mathrm{O}^{+}$reagent ions, a drift tube where analyte VOCs undergo ionisation and an orthogonal acceleration reflectron time-of-flight mass analyzer and multi-channel plate detector. The instrument was operated at a drift tube pressure of $2.2 \mathrm{mbar}$, drift tube temperature of $600^{\circ} \mathrm{C}$ and drift tube voltage of $600 \mathrm{~V}$, resulting in an operating $E / N$ ratio of $\sim 135 \mathrm{Td}\left(1 \mathrm{Td}=10^{-17} \mathrm{~V} \mathrm{~cm}^{-2}\right.$; de Gouw and Warneke, 2007). Table 1 summarizes the relevant instrumental details. The high mass resolution of the instrument $(m / \Delta m>4200$ at $m / z 21.022$ and $>4800$ at $m / z$ 205.195) and detection limit of few tens of ppt permitted identification of several rarely measured or previously unmeasured compounds based on their monoisotopic masses.

The PTR-TOF-MS 8000 used in this work was installed in a room on the second floor of a building at the suburban measurement site at Bode, Kathmandu. Ambient air was sampled continuously from the rooftop ( $\sim 20 \mathrm{~m}$ above ground) through a Teflon inlet line that was protected with a Teflon membrane particle filter to ensure that dust and debris did not enter the sampling inlet. Teflon membrane particle filters similar to the ones used in the Kathmandu study have been used without issues in several previous PTR-MS VOC studies by some of the authors (e.g. Sinha et al., 2010), including at another South Asian site in Mohali, India (Sinha et al., 2014). The filters were changed on seven occasions during the 40-day deployment from 19 December 2012 to 30 January 2013. The inlet lines used in Kathmandu were prepared prior to deployment by continuous purging at different flow rates in the laboratory at Mohali for more than three days and zero air was sampled through these lines. After purging, the background signals were always comparable to background signals observed during direct injection of zero air without a long inlet line for the $\mathrm{m} / \mathrm{z}$ ion peaks reported in this work. Bearing in mind that the ambient air (range of ambient temperature: $5-15^{\circ} \mathrm{C}$ ) was drawn in under 25 seconds (residence + sampling time; determined by spiking the inlet with sesquiterpenes emitted from an orange peel) into the PTR-TOF-MS, the probability of inlet effects for sticky compounds is not high. In any case, the part of the inlet line that was indoors was well insulated and heated to $40^{\circ} \mathrm{C}$ all the time to ensure there were no condensation effects. Instrumental background checks using zero air were performed at intervals of 3-4 days during the campaign.

Data acquisition of mass spectra was accomplished using the TofDaq software (version 1.89; Tofwerk AG, Switzerland). This software controls the timing of the pulser (used to pulse the ions produced in the drift tube and channel them into the time-of-flight region) and stores the raw data as a series of mass spectra in HDF5 format along with relevant instrumental metadata. The raw mass spectral data were then analysed using the PTR-MS-viewer software (version 3.1; Ionicon Analytic GmbH, Innsbruck, Austria) enabling peak search, peak fits and mass assignments. Mass axis calibration was accomplished using the following intrinsic ions: $\mathrm{H}_{3}^{18} \mathrm{O}^{+}$(monoisotopic mass 21.022) and $\mathrm{H}_{3}^{18} \mathrm{O}^{+} \cdot \mathrm{H}_{2} \mathrm{O}$ (monoisotopic mass 39.033 ). In addition, the transmission values of benzene $(m / z=79.054)$, toluene $(m / z=93.070)$, xylenes $(m / z=107.086)$, trimethylbenzenes $(m / z=121.101)$, dichlorobenzene $(m / z=146.976)$ and trichlorobenzene $(m / z=180.937)$ were employed. Further analysis of the data set was carried out using the IGOR Pro software (version 6.0; WaveMetrics, Inc.).

The instrument was calibrated twice (10 and 15 January 2013) during the field deployment by dynamic dilution of VOCs using a 17-component VOC gas standard (Ionimed Analytik $\mathrm{GmbH}$, Austria at $\sim 1 \mathrm{ppm}$; stated accuracy better than $8 \%$ ). Calibration for these seventeen VOCs namely formaldehyde, methanol, acetonitrile, acetaldehyde, ethanol, 
acrolein, acetone, isoprene, methacrolein, 2-butanone, benzene, toluene, o-xylene, chlorobenzene, $\alpha$-pinene, 1,2 dichlorobenzene and 1,2, 4-trichlorobenzene were carried out in the range of $2-10 \mathrm{ppb}$ at various relative humidities $(\mathrm{RH}=60,75$ and $90 \%)$. RH was controlled as per the details provided in Kumar and Sinha (2014). In order to determine the instrumental background at all relevant $m / z$ channels, VOC free zero air was produced by passing ambient air through an activated charcoal scrubber (Supelpure HC, Supelco, Bellemonte, USA) and a VOC scrubber catalyst maintained at $350{ }^{\circ} \mathrm{C}$ (GCU-s 0703, Ionimed Analytik GmbH, Innsbruck, Austria). Following the procedure of Stockwell et al. (2015), the measured ion signals were normalised to $\mathrm{H}_{3} \mathrm{O}^{+}(m / z=19)$ primary ions according to the following equation:

ncps $=\frac{I\left(\mathrm{RH}^{+}\right) \times 10^{6}}{I\left(\mathrm{H}_{3} \mathrm{O}^{+}\right)} \times \frac{2}{P_{\text {drift }}} \times \frac{T_{\text {drift }}}{298.15}$.

The two calibration experiments made during the course of the campaign did not show any change in the VOC sensitivities (values were within the precision error) as instrumental operational conditions were not changed. Usually, the sensitivity response of VOCs in a PTR-MS remain remarkably stable if instrumental operational conditions are not changed. This is supported by several previous studies (de Gouw and Warneke, 2007) including our own group's recent studies in the South Asian environment which involved a 3-year study (Chandra and Sinha, 2016) and a month-long study (Sinha et al., 2014). Large changes in ambient humidity are known to affect the sensitivity of some VOCs (e.g. benzene, methanol). This occurs due to a change in the abundance and ratio of the primary reagent ions $\left(\mathrm{H}_{3} \mathrm{O}^{+} ; m / z=19\right)$ and the hydrated hydronium ions $\left(\mathrm{H}_{3} \mathrm{O}^{+} \cdot \mathrm{H}_{2} \mathrm{O} ; m / z=37\right)$ within the drift tube (de Gouw et al., 2003). It assumes importance when ambient RH has large variability (e.g. very dry $<20 \%$ $\mathrm{RH}$ to very humid $>80 \% \mathrm{RH})$ during the measurements (e.g. during airborne measurements) and when the ratio of $\mathrm{m} 37 / \mathrm{m} 19$ in the drift tube is typically more than $10 \%$. For the measurements reported in this study, the ratio of the hydrated hydronium ions $\left(\mathrm{H}_{3} \mathrm{O}^{+} \cdot \mathrm{H}_{2} \mathrm{O}\right.$; nominal $m / z=37$ ) to the primary ions $\left(\mathrm{H}_{3} \mathrm{O}^{+}\right.$; nominal $\left.m / z=19\right)$ was lower than $10 \%$, for more than $92 \%$ of the data set and the ratio never exceeded $16 \%$. For the conditions during the campaign, our calibration experiments did not reveal significant humidity dependence for the VOC sensitivities $\left(n c p s p^{-1}\right)$. Moreover, as reported in de Gouw and Warneke (2007) and Sinha et al. (2009), it is the absolute humidity content of the sampled air rather than the RH, which is responsible for changes in detection sensitivity of certain VOCs within the PTR-MS. The sensitivity dependence has been reported in numerous studies as function of RH because RH is more frequently used in meteorology and for no changes/small changes in temperature, RH is a good proxy of the absolute humidity. We note that during the Kathmandu deployment, while the RH variability was large $(35-100 \%)$ most of the RH change was on account of changes in the ambient temperature rather than changes in absolute humidity of sampled air. The variability in the absolute humidity was only in the range of $20 \%$ between 19 December 2012 and 30 January 2013. Figure 3 shows the sensitivities (ncps ppb ${ }^{-1}$ ) for acetonitrile (a biomass burning tracer), acetaldehyde (an oxygenated compound), isoprene (a biogenic tracer) and benzene (an aromatic compound) at different $\mathrm{RH}$ regimes (60, 75 and $90 \%$ ) during the calibration experiments. In all cases an excellent linearity $\left(r^{2}=0.99\right)$ was observed. Hence the sensitivity (ncps ppb ${ }^{-1}$ ) derived at $90 \%$ RH was applied for converting the measured normalised counts per second to ppb and no further humidity corrections were deemed necessary.

In order to derive the sensitivity for the sum of monoterpenes, which have a molecular ion peak at $m / z=137.132$ and for which fragmentation results in ion signals at $m / z$ 81.070 and $m / z$ 137.132, the signal measured at $\mathrm{m} / \mathrm{z}$ 137.132 was scaled by 2.63 , as calibrations at the instrumental settings employed in the study clearly showed that $38 \%$ of the total molecular ion signal for monoterpene was detected at $m / z=137.132$, consistent with fragmentation patterns reported previously by Tani et al. (2004) for similar reaction conditions in the drift tube.

Variable background concentrations were observed for both formaldehyde and methanol while sampling zero air during the calibration experiments. Hence for these two compounds and all the other compounds not present in the 17component VOC gas standard but reported in this work, sensitivity factors were determined following the example of Stockwell et al. (2015), wherein calculated mass-dependent calibration factors based on linearly approximated transmission curve fits for oxygenated VOCs and hydrocarbons were employed. Figure S1a in the Supplement shows the linearly fitted mass-dependent transmission curve (black markers and dotted line) overlaid with the sensitivity factors of the calibrated compounds. Using linear approximations, massdependent calibration factors were determined separately for oxygenates (Fig. S1b in the Supplement) and hydrocarbons (Fig. S1c in the Supplement) in keeping with their different mass-dependent behaviour. For masses with heteroatoms other than oxygen, mass-dependent sensitivity factors were determined based on approximations used for the oxygenated compounds. For acetic acid, the sum of the signals at $\mathrm{m} / \mathrm{z}$ 61.207 (parent ion peak) and $m / z 43.018$ (fragment of the parent ion) were used to derive an upper limit for its ambient concentration.

The limit of detection was defined to be $2 \sigma$ of the measured normalised signal (ncps) while measuring VOC free zero air divided by the sensitivity expressed in ncps ppb (Sinha et al., 2014). The total uncertainty for calibrated compounds was calculated using the root mean square propagation of the accuracy error of the VOC standard, the mass flow controller's flow fluctuations during the calibration and the instrumental precision error $(2 \sigma$ while measuring $2 \mathrm{ppb}$ of the compound). Using this approach, all calibrated VOCs 

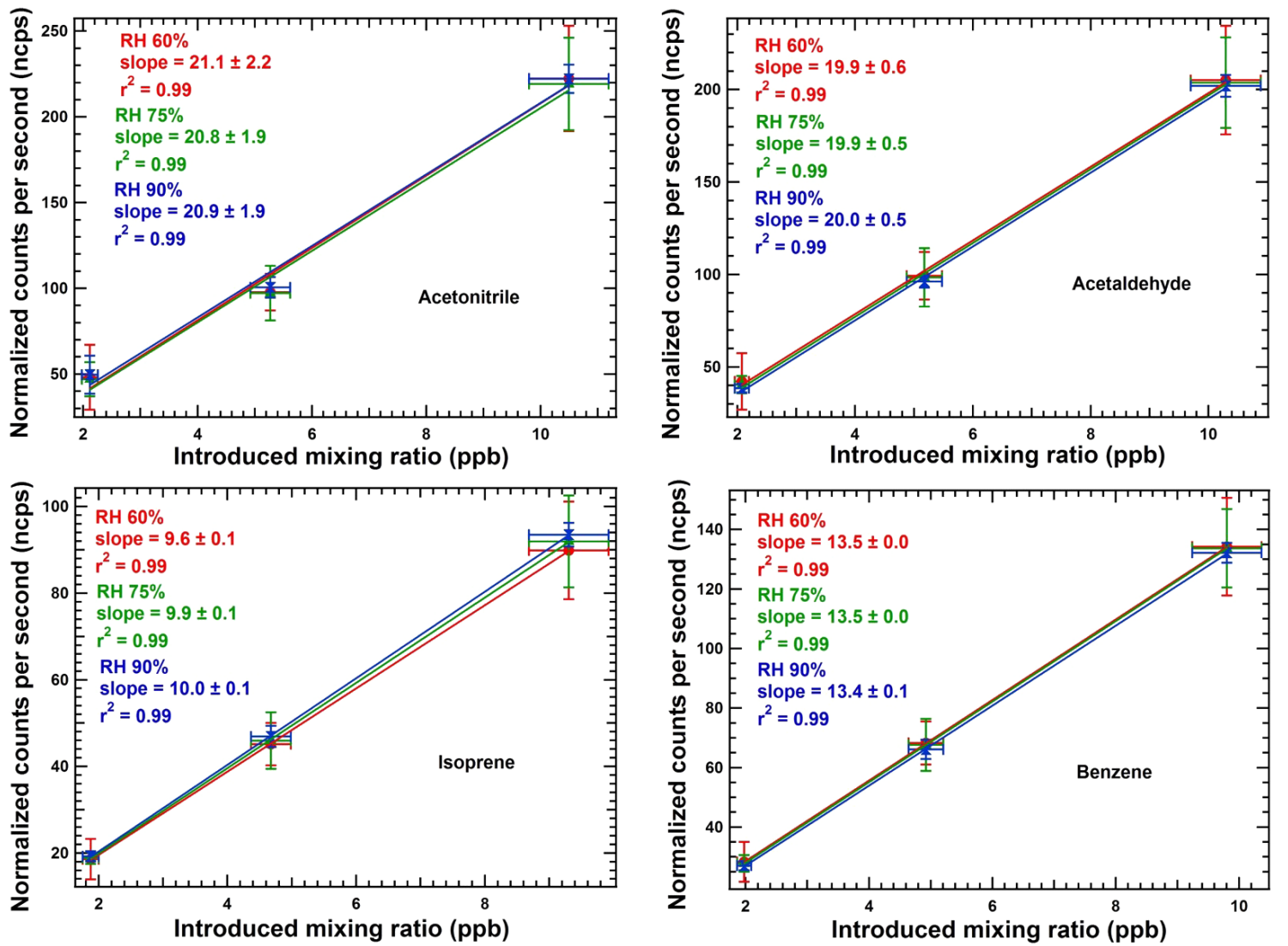

Figure 3. Compound specific normalised sensitivities at different relative humidities (RH 60, 75 and $90 \%$ ) for acetonitrile, acetaldehyde, isoprene and benzene during the calibration experiment performed on 10 January 2013. Horizontal bars reflect the error due to the MFC flows and the accuracy of the VOC gas standard whereas vertical bars reflect the precision error $(2 \sigma)$ of the measurements.

had a total uncertainty of $<20 \%$ (e.g. acetaldehyde $9.9 \%$, acetone $9.6 \%$, isoprene $15.4 \%$, benzene $9.4 \%$ and toluene $8.9 \%$ ), whereas for the other compounds reported in this work that could not be calibrated we estimate an overall uncertainty of $\sim 50 \%$ as also proposed by Stockwell et al. (2015) using a similar approach for quantification.

\section{Results and discussion}

\subsection{Identification of VOCs present in ambient air using PTR-TOF-MS mass scans}

The PTR-TOF-MS deployed in this study was operated over the range of $21-210 \mathrm{Th}$, with a mass resolution $(m / \Delta m>$ 4200 at $m / z=21.022$ and $>4800$ at $m / z=205.195$ ) sufficient to identify several compounds based on their monoisotopic masses. A maximum of 71 ion peaks $(m / z)$ were observed in the mass spectra during the measurement period for which the measured ambient concentrations exceeded the detection limit. Among these 71 species, 37 compounds/species had an average concentration greater than or equal to $200 \mathrm{ppt}$ during the study period. The molecular formula of com- pounds/species corresponding to these 37 ion peaks are listed in Table S1 in the Supplement. Additionally Table S1 in the Supplement also provides the (1) identity of plausible organic/fragment ions (e.g. $\mathrm{NO}_{2}^{+}$due to $\mathrm{C} 1-\mathrm{C} 5$ alkyl nitrates), (2) sensitivity, (3) limit of detection and (4) average $\pm 1 \sigma$ variability of ambient mixing ratios observed during the study period.

In order to minimise ambiguity arising due to multiple species or fragment ions contributing to ion peaks at a given $\mathrm{m} / \mathrm{z}$ ratio, the following quality control measures were employed for attribution of mass identifications to the observed ion peaks. (1) Ion peaks for which the observed mass spectra had competing/major shoulder peaks in a mass bin width of $0.005 \mathrm{amu}$ centred at the relevant monoisotopic ion peak were excluded from exclusive mass assignments. (2) Next, the ambient time series of the observed ion peak assigned after step 1 was carefully examined and cases where the concentration profile was completely flat/showed no ambient variability were also excluded from mass assignments. (3) Finally, the concentration profiles of the ion peaks ascribed to rarely reported or new compounds after step 1 and step 2 were compared to the ambient time series and diel profiles 
of more frequently/regularly quantified VOCs, such as acetonitrile, isoprene, benzene, toluene, acetone and acetaldehyde, as their diel profiles would likely indicate the driving processes and emission sources of the compounds. During the PTR-TOF-MS field deployment, instrumental background checks revealed backgrounds as high as $170 \mathrm{ppt}$ at certain $m / z$ channels (e.g. $m / z$ 125.958, $m / z$ 90.947, $m / z$ 108.957). Therefore, the $200 \mathrm{ppt}$ cut-off was chosen as an additional quality control measure so as to ensure attribution of ion peaks in the mass spectra only to the compounds present in the ambient air and not due to instrumental reasons. The 37 compounds that were identified accounted for $86.7 \%$ of the total mass due to all 71 ion peaks detected in the mass spectra.

In cases where the contributions of isotopologues were significant (e.g. acetic acid $m / z=61.027$ and nitromethane $m / z=62.026$ ), the signal at the concerned $m / z$ was duly corrected (Inomata et al., 2014). Potential interferences due to isotopic contributions (e.g. ${ }^{13} \mathrm{C}$ ) were also corrected whenever applicable. Out of these 37 ions which were identified with reasonable confidence, 8 contained nitrogen, 15 were oxygenated compounds, 13 were hydrocarbons and 1 contained sulfur. Two ion peaks $(\mathrm{m} / \mathrm{z}=51.044$ and $m / z=56.060)$ could not be identified based on the exact protonated monoisotopic $m / z$ and for these, the closest contenders, namely 1,3-butadiyne $(m / z=51.023)$ and propanenitrile $(m / z=56.050)$, were tentatively assigned. Two "new" compounds, which to the best of our knowledge have not been reported in any previous study, namely formamide $\left(\mathrm{CH}_{3} \mathrm{NO}\right.$; protonated $\left.m / z=46.029\right)$ and acetamide $\left(\mathrm{C}_{2} \mathrm{H}_{5} \mathrm{NO}\right.$; protonated $\left.m / z=60.051\right)$, were also detected. We discuss their diel variability and potential sources in Sect. 3.5 along with some of the other rarely reported compounds in ambient air. Figure S2 in the Supplement shows illustrative mass spectra for isocyanic acid, which demonstrates that it is the major contributor in the relevant mass bin. Considering that some loss of isocyanic acid can occur due to hydrolysis in the drift tube, our measurements may be a lower limit of the ambient concentrations of isocyanic acid.

The total reactive carbon calculated as the sum of the average mixing ratios of all the 37 compounds reported in this study was $175.8 \mathrm{ppbC}$, of which 15 compounds alone contributed $145.4 \mathrm{ppbC}$ ( $83 \%$ of the total) and are listed in Table S2 in the Supplement. Propyne, acetaldehyde, benzene, acetic acid, acetone, propene and toluene collectively composed more than $60 \%$ of the measured reactive carbon.

In Sect. 3.2 and 3.4, we examine the general trends and diel concentration profiles of the most abundant VOCs to gain more detailed insights into the emission sources and chemistry of VOCs in wintertime air of the Kathmandu Valley.

\subsection{General trends in VOC concentrations during the SusKat-ABC campaign}

Figure 4 shows the general trends in VOC mixing ratios (as $1 \mathrm{~min}$ temporal resolution data) during the period of study from 19 December 2012 to 30 January 2013. While the top panel represents the time series in mixing ratios of oxygenated VOCs namely methanol, acetaldehyde and the sum of acetone and propanal, the second and third panels show mixing ratios of isoprene, acetonitrile and furan. The bottom panel shows the mixing ratios of benzene, toluene, sum of C8-aromatics (xylenes and ethylbenzene) and sum of C9-aromatics (trimethylbenzenes and propylbenzenes). All these compounds collectively accounted for about $50 \%$ (total $85.4 \mathrm{ppbC}$ ) of the total reactive carbon and are amongst the most abundant VOCs known to be present in the air influenced by urban emissions.

It can be seen that the time series was characterized by two contrasting periods in terms of chemical emission signatures: period 1 (shaded in pale yellow in Fig. 4; 19 December 2012-2 January 2013) and period 2 (shaded in grey in Fig. 4; 4-18 January 2013). Period 1 was characterized by high mixing ratios of isoprene ( $>3 \mathrm{ppb}$ ) during daytime and low acetonitrile mixing ratios relative to the remainder of the measurement period (generally $<2 \mathrm{ppb}$ except for a plume on 28 December 2015 which was suspected to be due to garbage burning in the local vicinity), while period 2 was marked by a decrease in the amplitude of daytime isoprene and a significant increase in mixing ratios of acetonitrile (typically $>3 \mathrm{ppb}$ ) and benzene (typically $>10 \mathrm{ppb}$ ). The global budget of isoprene is dominated by emission from vegetation (500 $\mathrm{Tga}^{-1}$; Guenther et al., 2006), in most cases as a function of photosynthetic active radiation and temperature. Clearly, in the early part of this winter campaign, conditions were favourable for significant isoprene emissions from vegetation. It is worth mentioning that oak and Melia azedarach were present in the forested regions upwind of the site and are high isoprene emitters (Geron et al., 2001). As the ambient temperature and radiation decreased and early morning fog became frequent during the first half of January, biogenic emissions reduced in intensity $(<2 \mathrm{ppb})$. Leaf fall in deciduous trees by the end of December and more frequent leaf litter burning were likely important contributors to reduced isoprene and increased acetonitrile emission in the second half of the campaign. While the highest isoprene concentrations were driven by biogenic sources, biomass burning sources also emitted isoprene, a finding consistent with reports from another South Asian site at Mohali, India (Sinha et al., 2014).

All the brick kilns in the Kathmandu Valley are brick Fixed Chimney Bull Trench Kilns (FCBTKs), except for one vertical-shaft brick kiln and two Hoffmann-designed brick kilns. FCBTKs are operated around the clock, from the first week of January to mid-April, according to our survey. Thus, our deployment fortuitously was able to contrast the periods 


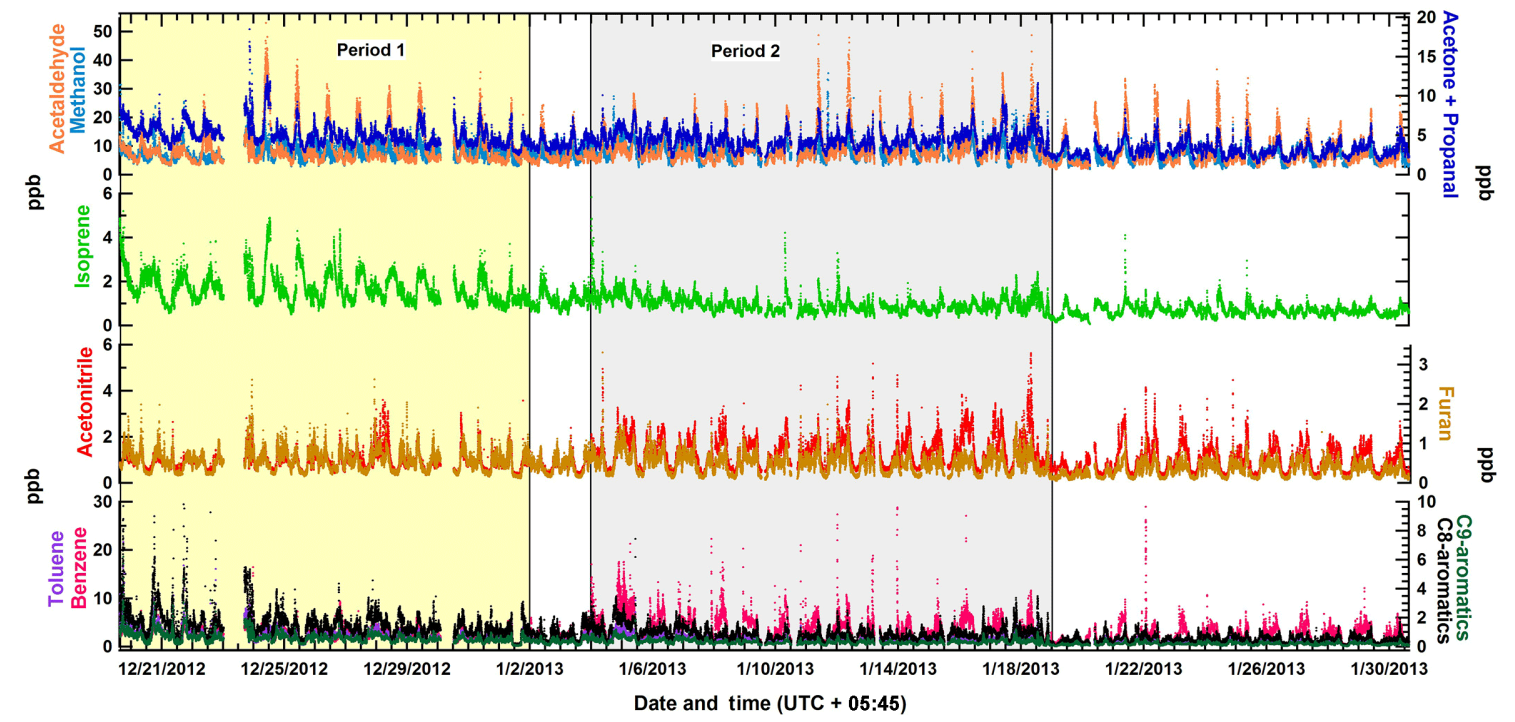

Figure 4. Time series of 1 min time resolution data for the mixing ratios of methanol, acetaldehyde and the sum of acetone and propanal (top panel); isoprene (second panel from top); acetonitrile and furan (second panel from bottom); and benzene, toluene, the sum of C8-aromatics (xylene isomers and ethyl benzene) and the sum of C9-aromatics (isomers of trimethyl benzenes and propyl benzenes) (bottom panel) during the SusKat-ABC campaign.

marked by the presence and almost complete absence of operational brick kilns in the fetch region of our measurement site. Most open burning and cooking activities remain similar in December and January. Due to reduced leaf fall in January (leaf fall of deciduous trees picks up in November and peaks in December) the open burning of leaf litter with other waste is generally less in January. With regard to increased open biomass burning from other sources in January, the first week of January was the coldest period of the deployment, so one could hypothesise that the higher emissions in this period were due to more open fires being lit to keep warm. However, as can be seen in Fig. 4, the biomass burning emissions were much higher for most of January (including a rain event during 18 January 21:00-19 January 01:00 LT). Thus, the brick kiln activity is the singular feature that is prominently different between both the periods.

To the best of our knowledge and survey, the fuel burnt in the brick kilns does not differ much between the brick kilns though the type of biofuel employed during different times in a year can vary depending on the availability and abundance of certain types of biofuel. One common biofuel used in the brick kilns is the seed of the lapsi fruit (Choerospondias axillaris). This emission activity appears to have been captured quite well in the time series profile of acetonitrile, for which the major emission source is biomass burning (Holzinger et al., 1999; Sarkar et al., 2013; Sinha et al., 2014). It was also interesting to note the similarities in the time series of furan $(\sim 1 \mathrm{ppb})$, another combustion tracer, with acetonitrile. Biomass burning and biofuel use contribute to half of the global budget of benzene (Henze et al., 2008; Andreae and Merlet, 2001; Sarkar et al., 2013) and it appears that brick kilns in Kathmandu being co-fired with biomass as fuel were a major source of benzene. A recent study by Al-Naiema et al. (2015) reported reduction in emissions ( $\sim 40 \%$ reduction of fossil $\mathrm{CO}_{2}$, particulate matter and heavy metal emissions) when co-firing of oat hull biomass with coal was carried out for generation of electricity in the USA. We note that the case study did not investigate co-emissions of toxic VOCs such as isocyanic acid, formamide, acetamide, nitromethane and naphthalene, which were associated with emissions from biomass co-fired brick kilns in the Kathmandu Valley. A study conducted by Clean Energy Nepal (Raut, 2003) showed that $8 \mathrm{~h}$ averaged concentrations of air pollutants such as total suspended particulate (TSP), $\mathrm{PM}_{10}, \mathrm{SO}_{2}$ and $\mathrm{NO}_{x}$ were 3 times higher during the brick kiln operating period relative to the period they were not operational at the same location. Significant differences exist between the electricity generation unit studied by AlNaiema et al. (2015) and the typical biomass co-fired brick kilns that dot the Kathmandu Valley in terms of design, combustion efficiency, biomass fuel being co-fired and the end application. Thus though the same word "co-firing" is used colloquially, these are really different from an operational and environmental standpoint, with one being an efficient closed unit set-up that employs good scrubbers whereas the other has numerous vents and combustion characteristics that are hardly comparable.

It is also worth mentioning that the hotspot and regional haze imagery obtained using MODIS Terra satellite (at a spatial resolution of $500 \mathrm{~m}$ and time resolution of $5 \mathrm{~min}$ at 05:00-06:00 LT) between 19 December 2012 and 30 January 2013 (data accessed at NASA worldview; 
http://worldview.earthdata.nasa.gov/) were similar except for a 6-day period (12-17 January 2013), wherein the regional haze was stronger. We note that calmer meteorological conditions could be a potential contributory factor for stronger haze in this period. The MODIS satellite image did not detect any active fire counts (at greater than $85 \%$ confidence limit) over the Kathmandu Valley (latitude $27.7^{\circ} \mathrm{N}$ ) during the whole campaign period (19 December 2012-30 January 2013). Thus, the higher chemical concentrations observed from 4 to 18 January and even later appear to be linked to the re-start of the biomass co-fired brick kilns and cannot be explained by linkages with regional haze or increased open burning of biomass, considering the available evidence. We analyse the diel profiles for the two contrasting periods and some of these aspects in detail in Sect. 3.4.

In the time series it can also be seen that 19 January 2013 was characterized by the lowest VOC concentrations because of an intense rain event during the previous night. When considering the entire study period, high concentrations of OVOCs were typically observed in the early morning hours between 08:00 and 10:00 LT and, surprisingly, acetaldehyde, which is the most reactive VOC among the OVOCs, frequently reached concentrations as high as $40 \mathrm{ppb}$. In contrast methanol and the sum of acetone and propanal were generally below 20 and $10 \mathrm{ppb}$ respectively. Peak acetaldehyde concentrations of about $30-40 \mathrm{ppb}$ were observed in the time series. These often correlated with peaks in the concentrations of acetonitrile and furan (chemical tracers for combustion) between 4 January 2013 and 30 January 2013 and occasionally with peaks in daytime isoprene concentrations before 2 January 2013. Biomass burning sources and photooxidation of precursor compounds co-emitted from the biomass burning appear to contribute significantly to the high concentrations of oxygenated VOCs. This points to the fact that the major sources of oxygenated VOCs during wintertime in Kathmandu are different from what are generally considered to be the most important sources based on studies conducted in several other regions of the world, where photooxidation and industrial sources dominate and have large implications for wintertime oxidation chemistry in the valley, as these species play a key role in radical chemistry (Singh et al., 1995). For example, the observed ranking in oxygenated VOCs is different from the ranking observed during wintertime in megacities like Paris and London (methanol $>$ acetaldehyde $>$ acetone) (Dolgorouky et al., 2012; Langford et al., 2010). Furthermore the ranking observed for aromatic VOCs during this study (benzene $>$ toluene $>$ sum of C8aromatics $>$ sum of $\mathrm{C} 9$-aromatics) was in contrast to the ranking (toluene $>$ benzene $>$ sum of $\mathrm{C} 8$-aromatics $>$ sum of C9-aromatics) observed in several urban sites such as Paris, London and Tokyo (Dolgorouky et al., 2012; Langford et al., 2010; Yoshino et al., 2012). This exemplifies that the nature and strength of emission sources for oxygenated and aromatic VOCs in the Kathmandu Valley differ from several urban areas in other parts of the world. Biomass burning sources and the manner in which regulation of benzene occurs are likely the major causes for the observed differences.

\subsection{Comparison with wintertime VOC mixing ratios elsewhere}

Figure 5 provides a comparison during the winter season of average VOC mixing ratios measured in the Kathmandu Valley with VOC mixing ratios reported at other urban or urban-influenced environments including megacities. The concentration ranking in the average VOC mixing ratios during our wintertime deployment was acetaldehyde $(8.8 \mathrm{ppb})>$ methanol $(7.4 \mathrm{ppb})>$ acetone + propanal $(4.2 \mathrm{ppb})>$ benzene $(2.7 \mathrm{ppb})>$ toluene $(1.5 \mathrm{ppb})>$ isoprene $(1.1 \mathrm{ppb})>$ acetonitrile $(1.1 \mathrm{ppb})>$ sum of $\mathrm{C} 8$-aromatics $(\sim 1 \mathrm{ppb})>$ furan $(\sim 0.5 \mathrm{ppb})>$ sum of C9-aromatics $(0.4 \mathrm{ppb})$. As can be seen from Fig. 5, when compared to average wintertime mixing ratios reported from several sites elsewhere in the world, the mixing ratios of acetaldehyde ( $\sim 9 \mathrm{ppb})$, acetonitrile $(\sim 1 \mathrm{ppb})$ and isoprene $(\sim 1 \mathrm{ppb})$ in the Kathmandu Valley are among the highest measured anywhere in the world. In contrast, Kathmandu had lower methanol mixing ratios than measured in London and Tokyo (Langford et al., 2010; Yoshino et al., 2012) during winter 2006 and 2007 (19.4 and 12.4 ppb respectively) as well as lower acetone mixing ratios than what was measured in Barcelona (8 ppb) (Filella and Peńuelas, 2006). Apart from the contribution of biogenic sources during daytime, which was major, isoprene was also emitted by biomass combustion sources in the Kathmandu Valley. Borbon et al. (2001) have previously reported that due to traffic emissions alone, isoprene mixing ratios can reach as high as $1.8 \mathrm{ppb}$ in urban areas. The Bode site was located in the outflow of Kathmandu metropolitan city and Lalitpur sub-metropolitan city and therefore the evening time increase in isoprene can also be partially due to traffic emissions during the evening rush hour. The average benzene concentrations in Kathmandu $(\sim 3 \mathrm{ppb})$ were notably higher than those reported in other cities except for the city of Karachi (Barletta et al., 2002). The average toluene and sum of $\mathrm{C} 8$-aromatic mixing ratios, however, were lower than in other urban areas like Tokyo (Yoshino et al., 2012), Barcelona (Filella and Peńuelas, 2006), Karachi (Barletta et al., 2002), Hong Kong (Guo et al., 2007) and Guangzhou (Liu et al., 2008), where industrial and traffic sources are much larger than in Kathmandu. Whereas benzene is emitted in almost equal proportion from fossil fuel and biomass combustion sources (Henze et al., 2008), fossil fuel combustion and industrial processes contribute a much larger fraction to the global budgets of toluene and sum of $\mathrm{C} 8$ and $\mathrm{C} 9$-aromatics. The observed trend in concentrations of some of the aromatic compounds measured using PTR-TOF-MS in this study differs from the trend reported in a previous study by Yu et al. (2008) who em- 

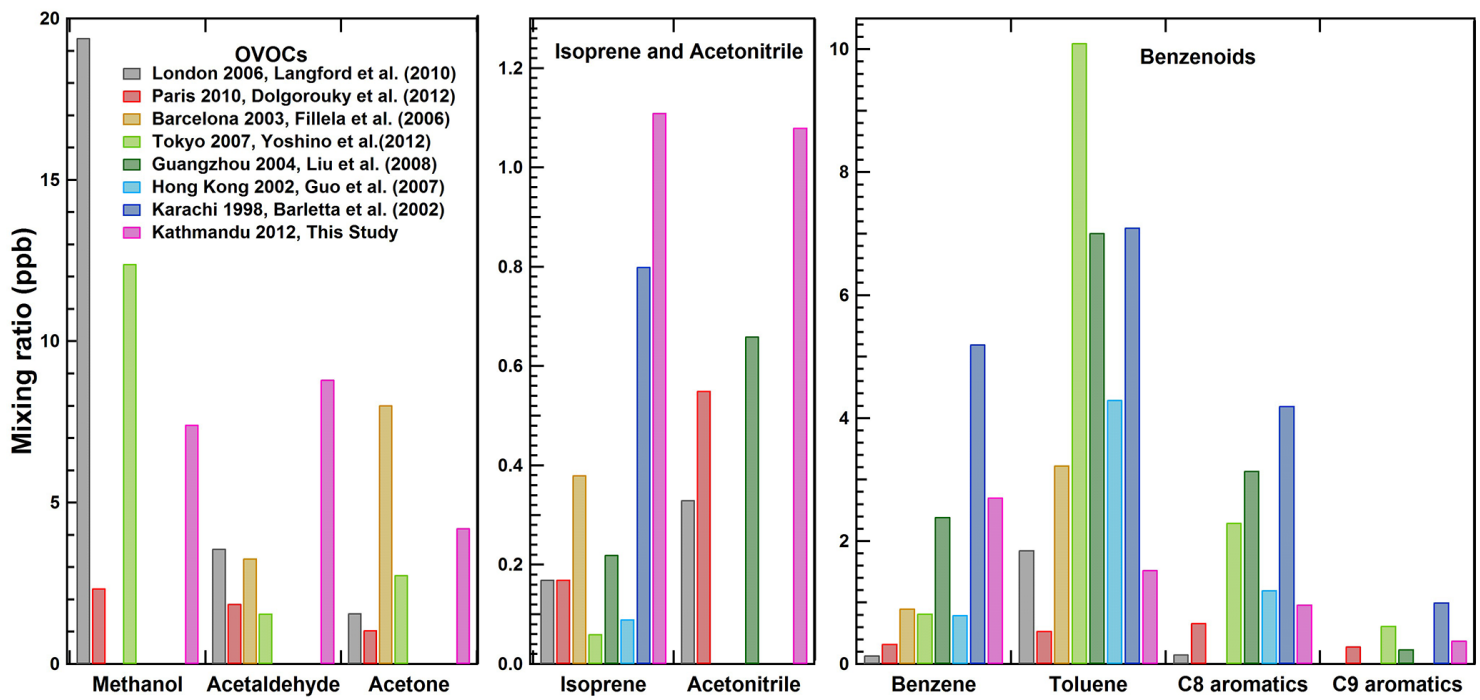

Figure 5. Comparison of wintertime VOC mixing ratios measured in the Kathmandu Valley with wintertime VOC mixing ratios at selected urban sites elsewhere in the world.
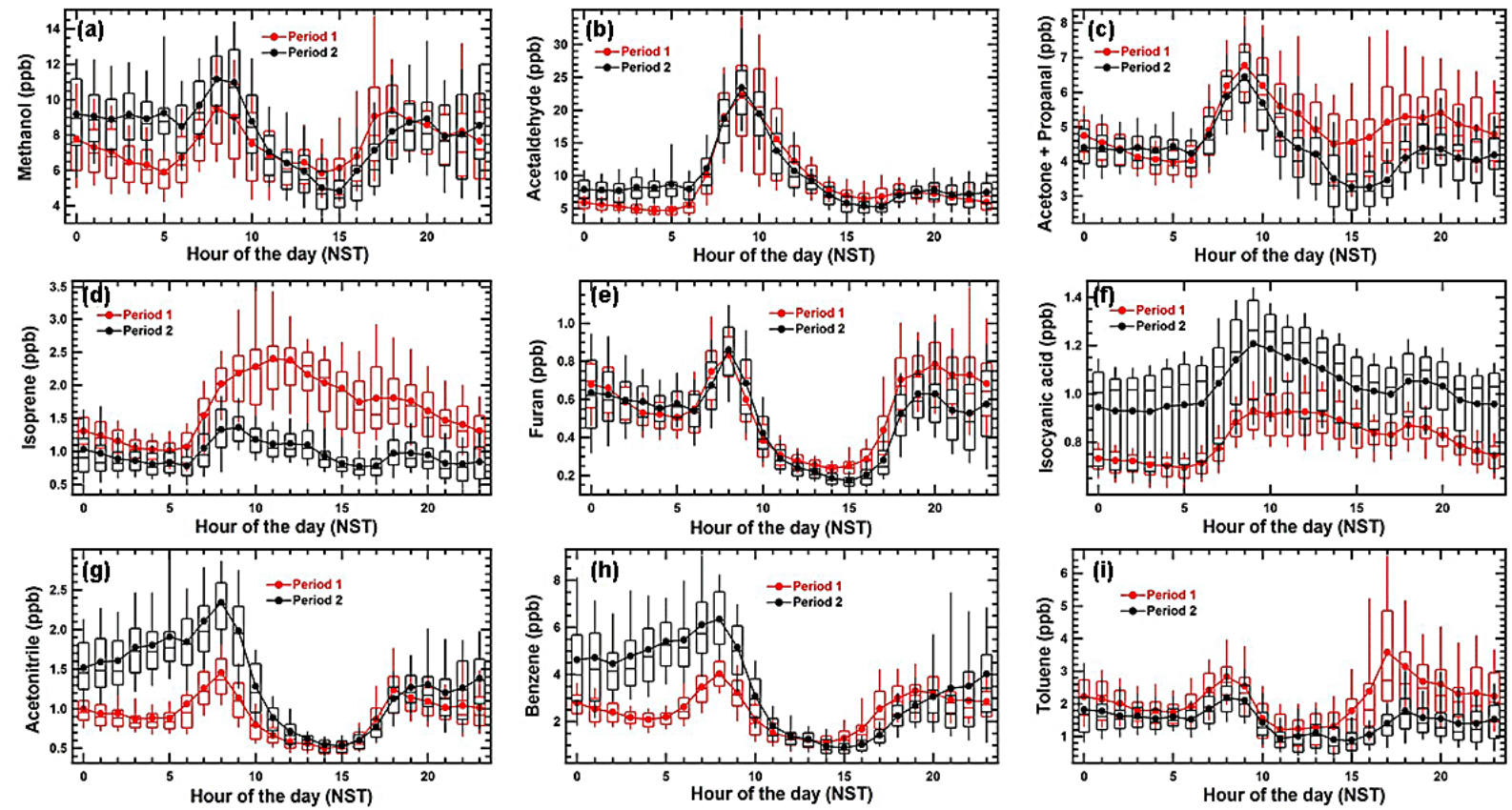

Figure 6. Box and whisker plots showing average, median and variability (10th, 25th, 75th and 90th percentile) for some major VOCs in the Kathmandu Valley during period 1 and period 2.

ployed the long-path DOAS technique to make measurements of monoaromatic VOCs in Kathmandu during winter 2003. In that study, xylene (a C8-aromatic compound) concentrations were reported to be the highest followed by toluene and benzene respectively. We think two reasons are responsible for differences from that study. The first reason is that the measurements by Yu et al. (2008) were carried out near a fairly busy road (Chabahil-Boudha-Jorpati road) and a traffic intersection (Chabahil-Ring Road intersection) and consequently the aromatic VOC concentrations were primarily influenced by traffic sources. Secondly, VOC measurements using the long-path DOAS technique are reported to have potentially large interferences due to ambient ozone and suspended particles (Yu et al., 2008).

Despite much larger populations and more industries compared to Kathmandu, wintertime measurements in the megacities of London (Langford et al., 2010) and Paris (Dolgorouky et al., 2012) suggest that the air is much cleaner 
for many of the VOCs shown in Fig. 5. The combination of the topography of Kathmandu (which results in suppressed ventilation) and the anthropogenic and biogenic emissions within the valley appear to cause high ambient wintertime concentrations for several VOCs (e.g. acetonitrile, acetaldehyde, benzene and isoprene).

\subsection{Diel profiles as a tool to constrain emission sources: VOCs emitted from biomass burning activities in the Kathmandu Valley}

In order to contrast the role of diverse emission sources during period 1 and period 2, we analysed the diel profiles of a number of VOCs. These are shown in Fig. 6 as box and whisker plots for period 1 (derived from total number of measurements $>20500$ ) and period 2 (derived from total number of measurements $>21500$ ) for methanol, acetaldehyde, sum of acetone and propanal, isoprene, furan, isocyanic acid, acetonitrile, benzene and toluene. The time stamp is the start time of respective hourly data bin (e.g. 9 for data averaged between 9 and 10).

We note that the concentrations of acetonitrile (a chemical tracer for biomass combustion), methanol, benzene and isocyanic acid are significantly higher in period 2 relative to period 1 , indicating that for all of them, the biomass cofired brick kilns that became operational in the first week of January and other forms of biomass burning (e.g. leaves and branches, garden waste and garbage) were major contributory sources. In contrast, isoprene and toluene concentrations were markedly higher during period 1 as compared to period 2. Acetaldehyde and furan did not differ much between period 1 and period 2 . The high acetaldehyde concentrations suggest the possibility of high levels of peroxy acetyl nitrate. The campaign average concentration of $1.08 \mathrm{ppb}$ observed at $m / z 45.990$ and attributed to $\mathrm{NO}_{2}^{+}$(Table S1 in the Supplement), which is a fragment ion of C1-C5 alkyl nitrates (Aoki et al., 2007), appears to be consistent with the presence of a large pool of gaseous organic nitrate species too. Except for isoprene, isocyanic acid and acetaldehyde, which did not show a marked bimodal profile (morning and evening maxima), all the other VOCs shown in Fig. 6 exhibited bimodal diel profiles to some degree, indicating the common influence of urban emission activities and biomass combustion sources for these compounds. Bimodal profiles for VOCs have previously been reported from several sites influenced by urban emissions (Staehelin et al., 1998; Stemmler et al., 2005), including our recent work in Mohali, India (Sinha et al., 2014), another site in South Asia that is somewhat closer to Kathmandu in terms of emission sources. Such bimodal profiles typically arise because morning and evening emissions get mixed into a shallow boundary layer, while the afternoon emissions are diluted under a rapidly growing boundary layer due to the surface heat flux, giving rise to a daytime minima in the diel profile. This holds for VOCs which are not formed photochemically or emitted anoma- lously during the daytime in large measure. Thus, bimodal diel profiles were not observed for isoprene which is emitted by terrestrial vegetation during daytime, and acetaldehyde and isocyanic acid, which are known to be emitted from biomass fires and produced photochemically from precursor compounds (Millet et al., 2010; Roberts et al., 2014). In general, for both period 1 and period 2, the features of diel profiles in terms of rise and fall of concentrations are similar for all the VOCs shown in Fig. 6. The diel profiles of all VOCs also reveal that, at about 06:00 LT, emission activities pertaining to cooking (use of biofuel and fossil fuel such as liquefied petroleum gas) and traffic pick up, which in combination with the brick kiln emissions appears to drive the diel peaks for almost all VOCs occur at around 08:00-09:00 LT.

In addition to the typical boundary layer dynamics and emissions driving concentration profiles, the mountain meteorology appears to play a key role in the concentration peaks observed after sunrise around 08:00-09:00 LT. If one examines the diel pattern for wind speed, wind direction, temperature and solar radiation data (available for part of the study and shown in Fig. 2b), it is clear that the diel meteorological conditions (e.g. surface wind flow, direction, temperature, RH) were very consistent even on different days as there is a very narrow spread in the values for each hour and the average and median always converged. The wind speeds were typically lower than $1 \mathrm{~ms}^{-1}$ for almost all hours of the day except between 10:00 and 16:00 LT, when westerly winds from the mountain passes lying west of the site swept across the valley, attaining wind speeds of $3-4 \mathrm{~m} \mathrm{~s}^{-1}$ and causing rapid venting and dilution. The wind direction was very consistent on daily timescales. During the evening and at night, the horizontal wind flow was mainly from the south-east direction, which changed to a westerly flow during the day. Downslope mountain winds during nighttime result in pooling of cleaner cold air. Then shortly after sunrise, convective mixing of surface air with residual air commences the growth of the well-mixed daytime boundary layer (Panday and Prinn, 2009).

The highest mixing ratios for acetaldehyde (average value of $\sim 25 \mathrm{ppb}$ for both period 1 and period 2) and acetone (average value of $\sim 7 \mathrm{ppb}$ for both period 1 and period 2) and indeed for most of the other VOCs were observed during morning hours about $1 \mathrm{~h}$ after sunrise (09:00-10:00 LT). The breaking of the nocturnal boundary layer and entrainment of air masses rich in accumulated oxygenated VOCs, which were displaced by cold air from the mountain slopes after midnight, contribute towards the peaks observed in all VOCs between 09:00 and 10:00 LT. In mountain basins such as the Kathmandu Valley, katabatic winds are generated at night due to radiative cooling of mountains that lead to pooling of cold air to the valley bottom (Fig. 2a). Due to this katabatic flow, less cold and less dense air parcels in the valley bottom containing the entire valley's surface emissions rise upward during nighttime, while relatively clean cold air parcels flow underneath. After sunrise, downward mixing of the up- 
lifted accumulated VOCs occurs with new surface emissions, as a growing mixed layer entrains the elevated layers of the polluted air. Therefore during morning hours, mixing of oxygenated VOCs and their precursors, which had accumulated during nighttime and the kickstart to their photochemical production after sunrise, contributes to sharp peaks (e.g. for acetaldehyde and acetone). It should also be noted that the majority of the population in Kathmandu Valley cook their main meals in the morning and evening hours using fuel such as liquefied petroleum gas, kerosene and firewood (Panday et al., 2009).

Contributions from biogenic sources and oxidation of alkenes to acetaldehyde are also important. The reaction of oxygenated VOCs like ethanol and methyl ethyl ketone with hydroxyl $(\mathrm{OH})$ radicals and the reaction of tropospheric ozone $\left(\mathrm{O}_{3}\right)$ with alkenes can significantly contribute to photochemical formation of acetaldehyde (Sommariva et al., 2011; Grosjean et al., 1994). After the morning peak (09:0010:00 LT), a sharp decrease was observed in the average acetaldehyde mixing ratios (from $\sim 25$ to $\sim 8 \mathrm{ppb}$ during 10:00-13:00 LT) relative to methanol and acetone, which is not surprising considering its much higher $\mathrm{OH}$ reactivity.

The highest isoprene concentrations were observed during daytime for both period 1 and period 2 but the average concentrations were much higher during period 1 when ambient temperature and solar radiation were comparatively higher and deciduous trees had not shed much of their leaves. This clearly points to daytime biogenic emission sources of isoprene in the Kathmandu Valley. In Sect. 3.6 we investigate the spatial and temporal location of the biogenic sources. We note that while the isoprene emission profile was dominated by biogenic sources, biomass burning (Christian et al., 2003; Andreae and Merlet, 2001; Warneke et al., 2011) and traffic (Borbon et al., 2001) also contributed to the ambient isoprene as can be seen from the nighttime peaks and discussed in previous sections. Thus, the contribution of both biogenic and anthropogenic sources resulted in high isoprene even in winter in the Kathmandu Valley, which is different from what has been observed at high-latitude sites in winter (Seco et al., 2011).

Apart from the biomass burning practices typical of developing regions of the world, the brick kilns in the Kathmandu Valley burn not only coal but also large quantities of wood and crop residues, ca. $90 \mathrm{t}$ per month per brick factory (Stone et al., 2010; Rupakheti et al., 2016), which can emit acetonitrile and benzene (Sarkar et al., 2013). Both acetonitrile and benzene levels were much higher during nighttime and morning hours in period 2 as compared to period 1 due to more intense biomass burning in period 2. During 08:0009:00 LT (when the highest ambient acetonitrile and benzene were observed), average mixing ratios were approximately 1 and $2 \mathrm{ppb}$ higher for acetonitrile and benzene respectively during period 2 relative to period 1 .

Unlike acetonitrile and benzene, toluene concentrations were higher during period 1 in comparison to period 2. De- spite the dilution effect of cold air descending from the mountain slopes, benzene concentrations increased during the night in period 2, whereas toluene concentrations did not show any increase during the night in both period 1 and period 2, suggesting that biofuel and biomass burning sources (including the brick kilns co-fired with biomass) and not traffic were the driving factors responsible for nighttime increase in benzene during period 2, probably due to varied forms of biomass combustion, including the biomass co-fired brick kilns. The emission ratios of benzene/toluene from previous studies show that, for a wide variety of commonly occurring fuels, the emission of benzene can be more than twice as high as the emission of toluene (Tsai et al., 2003; Lemieux et al., 2004; Stockwell et al., 2015). The use of large number of diesel generators as an alternative power source in the Kathmandu Valley, which suffers from scheduled daily power outages in some quarters of the city, could also have significant contributions to the observed high mixing ratios for aromatic VOCs.

To our knowledge, this paper reports the first measurements of isocyanic acid from any site in South Asia. Isocyanic acid has only recently been measured in ambient air using novel mass spectrometric methods (Roberts et al., 2011), and much remains to be understood regarding its sources and sinks in different environments. The high isocyanic acid concentrations observed during the daytime suggest a strong photochemical source from hydroxyl radical initiated oxidation of alkyl amines and amides with hydroxyl radicals (Roberts et al., 2011, 2014; Zhao et al., 2014). Isocyanic acid has also been detected in diesel exhaust (Wentzell et al., 2013), tobacco smoke and wild fires and in emissions from low-temperature combustion of coal (Nelson et al., 1996). From the diel profile, it is clear that around evening time there are primary emissions too, but overall the secondary source dominates the ambient concentrations of isocyanic acid in this environment. Currently, global models of isocyanic acid (Young et al., 2012) do not incorporate a photochemical source. The recent model-based estimates of isocyanic acid (HNCO) by Young et al. (2012) showed annual mean concentrations of HNCO over the Indo-Gangetic Plain and Nepal to be in the range of $0.2-0.5 \mathrm{ppb}$ (values read from Fig. 4 of Young et al., 2012). The average concentrations measured during winter in Kathmandu and in the postmonsoon season in Mohali were $\sim 1 \mathrm{ppb}$ (Chandra and Sinha, 2016) with clear daytime maxima. Our in situ field data from the Kathmandu Valley suggest that inclusion of isocyanic acid's photochemical sources is necessary for deriving better estimates of the global isocyanic acid budget, as these are likely to be significant over South Asia where biomass burning and agricultural activities can emit alkyl amines (Roberts et al., 2011). Serious health impairments can occur upon exposure to isocyanic acid at concentrations greater than $1 \mathrm{ppb}$, which occurred during our study for several hours during period 2 . These health impacts have been previously mentioned in Roberts et al. (2011) and are also discussed in Sect. 3.9. 

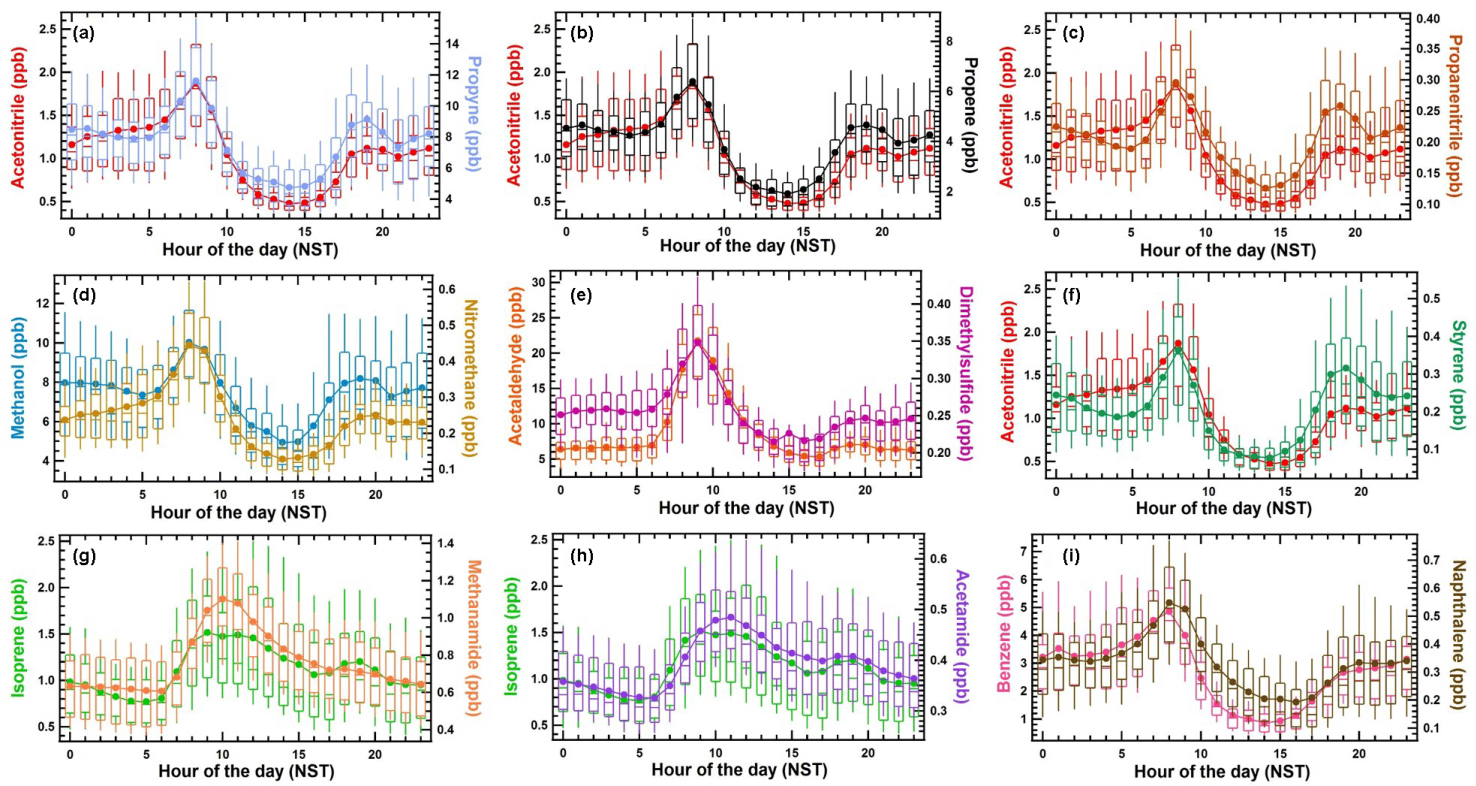

Figure 7. Comparison of diel box and whisker profiles of several rarely measured or previously unreported ambient VOCs with more frequently measured VOCs/emission tracers.

\subsection{Diel profiles of rarely measured VOCs and correlation with emission tracer VOC compounds for constraining their sources}

Figure $7 \mathrm{a}-\mathrm{c}$ show the diel profiles of propyne $(m / z=41.039)$, propene $(m / z=43.055)$ and propanenitrile $(m / z=56.060)$ alongside acetonitrile (an excellent tracer for biomass combustion) respectively. These diel profiles correspond to data for the entire measurement period. Strong correlation $\left(r^{2} \geq 0.7\right.$ for the hourly averages) with acetonitrile clearly indicates that during our wintertime study in the Kathmandu Valley, all these compounds were primarily emitted from biomass burning, despite having multiple sources (Hao et al., 1996; Akagi et al., 2011; Andreae and Merlet, 2001; Karl et al., 2003). Both propene and propyne participate in important chemical reactions in the troposphere. While propene is a source of $\mathrm{OH}$ radicals when it undergoes ozonolysis, propyne has been reported to produce methylglyoxal, formic acid and acetic acid in multistep reactions (Lockhart et al., 2013; Warneck and Williams, 2012). Propanenitrile has been previously detected in biomass smoke during laboratory studies (Akagi et al., 2011, 2013; Yokelson et al., 2013; Karl et al., 2003, 2007). Average propanenitrile mixing ratios observed during the measurement period were $\sim 0.21 \mathrm{ppb}$. Propanenitrile reacts very slowly with hydroxyl radicals in the atmosphere $\left(k_{\mathrm{OH}}\right.$ is of the order of $10^{-13} \mathrm{~cm}^{3}$ molecule ${ }^{-1} \mathrm{~s}^{-1}$ ) but the oxidation of propanenitrile with $\mathrm{OH}$ radicals can produce nitrogen compounds in the troposphere and hence could contribute to the reactive nitrogen budget.
Figure $7 \mathrm{~d}-\mathrm{f}$ show the diel profiles for nitromethane, dimethyl sulfide (DMS) and styrene alongside methanol, acetaldehyde and acetonitrile. Nitromethane (measured at $m / z$ ratio 62.026) concentrations correlated strongly with the hourly average concentrations of methanol $\left(r^{2}=0.81\right)$. Nitromethane is known to be present in diesel exhaust (Inomata et al., 2013, 2014; Sekimoto et al., 2013) and biomass burning plumes (Akagi et al., 2013). The maximum nitromethane mixing ratios observed in the Kathmandu Valley were $\sim 1.2 \mathrm{ppb}$, which falls within the range of ambient nitromethane mixing ratios (1-9 ppb) reported previously in urban environments (Grosjean et al., 1998; Yassaa et al., 2001; Inomata et al., 2014). In the Kathmandu Valley, a large number of diesel power generators are used to supplement the main power supply. Ambient nitromethane observed in the Kathmandu Valley is therefore also likely from a combination of biomass burning sources and diesel exhaust emissions. The major sink of nitromethane in the atmosphere is its photodissociation (photodissociation lifetime of $\sim 10 \mathrm{~h}$ ), which produces methyl radicals and $\mathrm{NO}_{2}$ (Taylor et al., 1980). Therefore nitromethane can act as a $\mathrm{NO}_{x}$ source in the atmosphere and could contribute to surface ozone production.

Dimethyl sulfide measured (at $\mathrm{m} / \mathrm{z}$ ratio 63.026) in the Kathmandu Valley showed good correlation with the diel profile of acetaldehyde (correlation of hourly averages: $\left.r^{2}=0.8\right)$. Average concentrations in the morning (09:0010:00 LT) reached $0.4 \mathrm{ppb}$. The oxidation of DMS with nitrate radicals at night would account at least in part for its lower nighttime concentrations of circa $0.2 \mathrm{ppb}$. Although marine phytoplankton emissions are known to be the major 

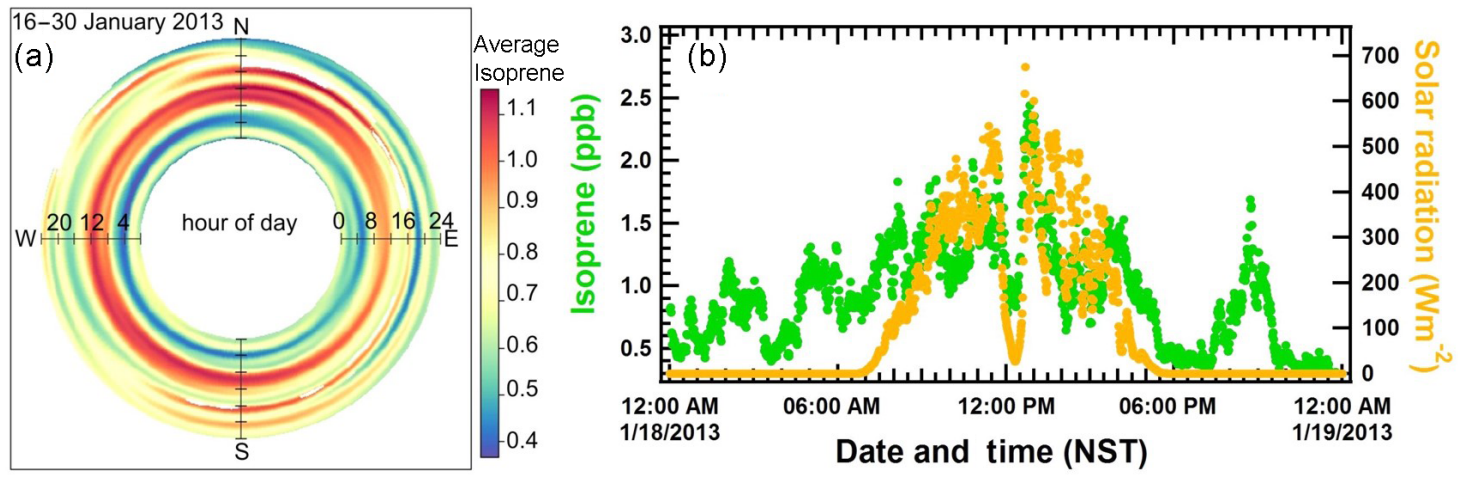

Figure 8. (a) Polar annulus plot of isoprene for the period 16-30 January 2013 highlighting the spatiotemporal variation of isoprene and its biogenic sources; (b) co-variation of daytime isoprene concentrations with solar radiation on 18 January 2013.

source of DMS in the atmosphere (Andreae and Raemdonck, 1983; Sinha et al., 2007), ambient mixing ratios up to $160 \mathrm{ppt}$ have been recently reported in the Amazon rainforest, which were attributed to biogenic soil emissions (Jardine et al., 2015). Certain lichens, mosses, grasses and plant leaves can emit acetaldehyde (Kesselmeier et al., 1997; Kesselmeier and Staudt, 1999). Therefore the possibility of such vegetation on the mountain slopes and the soil acting as sources of DMS and acetaldehyde respectively is plausible. Inefficient combustion of sulfur-rich biofuel/biomass are also potential sources of DMS (Jardine et al., 2015).

Figure $7 \mathrm{~g}$ and $\mathrm{h}$ show the diel profiles of formamide and acetamide alongside isoprene, while Fig. 7i shows the diel profile of naphthalene and benzene. During the measurement period, daytime maximum average values of $\sim 1$ and $\sim 0.5 \mathrm{ppb}$ were observed for formamide and acetamide respectively. Although formamide and acetamide correlate strongly with isoprene (hourly average $r^{2} \geq 0.8$ ), biogenic sources of formamide and acetamide have not been reported previously to our knowledge. However, short-chain amides such as formamide and acetamide can be produced as a result of photochemical oxidation of alkyl amines with hydroxyl radicals and nitrogen oxides $\left(\mathrm{NO}_{x}\right)$ (Roberts et al., 2014). The presence of formamide in ambient air at concentrations as high as $1 \mathrm{ppb}$ is consistent with the photochemical source of isocyanic acid discussed in the previous section. Also, it is reported that both formamide and acetamide could be emitted from tobacco smoke and hence likely from pyrolysis of biomass (Ge et al., 2011). The good correlation of formamide and acetamide with isoprene's diel concentration profile suggests that the photochemical source arising from oxidation of amines dominates over any primary emission sources of amides.

The ion peak detected at $m / z$ ratio of 129.070 in the PTRTOF-MS spectra was attributed to naphthalene. Naphthalene is the most volatile and abundant polycyclic aromatic hydrocarbon present in the atmosphere. Previously Martinez et al. (2004) have reported vehicle exhaust and residential heating in the urban environments as major sources of naphthalene. The similarity in diel profiles of naphthalene and benzene and their strong correlation with each other (hourly average $r^{2}=0.79$ ) suggest that biomass burning and traffic sources dominated emissions of naphthalene in the Kathmandu Valley.

\subsection{High isoprene in the Kathmandu Valley: a daytime biogenic source and contributions from combustion sources}

Figure 8a shows a polar annulus plot of the hourly mean isoprene mixing ratio during the period 16-30 January 2013 (unfortunately, meteorological data for other periods of the study are unavailable). The polar annulus plot is a method of visualising the temporal aspects of a species' concentration with respect to wind direction. In the polar annulus plots, measured concentrations are averaged in separate time and wind direction bins, and then further interpolation using the Kriging technique is applied for conversion to polar coordinates (Ropkins and Carslaw, 2012). Such plots reveal important spatiotemporal information regarding emission sources. In Fig. 8 it can be seen that isoprene had highest ambient mixing ratios ( $\sim 1 \mathrm{ppb}$ isoprene) during the daytime (07:00 14:00 LT), which is an indication of biogenic sources. Significant isoprene concentrations $(\sim 0.5 \mathrm{ppb})$ could also be observed during evening and nighttime which are likely from biomass combustion and traffic emission sources. Furan contributed a maximum of only $\sim 40 \%$ (during nighttime) to the sum of ambient isoprene and furan. This is a very important finding as previous studies using proton transfer reaction mass spectrometers equipped with quadrupole mass analyzers, which cannot distinguish between furan and isoprene peaks due to their lower mass resolution and which detect the two compounds collectively at a nominal $m / z=69$, tend to attribute the evening and nighttime concentrations to furan and not isoprene. Using a novel VOC-OHM chemical kinetics reactor (Kumar and Sinha, 2014), which constrained the rate coefficient of the isobaric contributor at nominal 
$m / z=69$, it has been demonstrated at another South Asian site in the north-western Indo-Gangetic Plain (Mohali) that isoprene is the major contributor to $m / z=69$. Thus it appears that isoprene has significant contributions from both vegetation and biomass/biofuel burning sources in South Asia, which has large implications for the atmospheric oxidation in this part of the world, as also discussed in Sinha et al. (2014). While several previous studies have reported significant contributions from anthropogenic sources to isoprene in urban areas elsewhere, especially in winter (Borbon et al., 2001; Barletta et al., 2005; Hellèn et al., 2012), the in situ measurements from Mohali and Kathmandu suggest that the magnitude of the isoprene source from anthropogenic sources may be quite important regionally in South Asia. Recently, Gilman et al. (2015) showed that in direct fire/smoke plumes from prescribed burns of selected biomass fuels common for the south-eastern, south-western or northern USA, the contributions of pentadienes and cyclopentene to isoprene concentrations measured using a PTR-QMS can be quite significant. Therefore, contributions from compounds such as pentadienes and cyclopentene to the isoprene concentrations measured in the Kathmandu Valley during evening, nighttime or early morning may be significant. The non-biogenic sources of isoprene acquire greater significance in the evening, nighttime or early morning when combustion emissions are more widespread and can accumulate under shallow inversions.

What is remarkable is that in contrast to wintertime measurements of isoprene from sites elsewhere in the world due to the strong contribution from biogenic sources in the Kathmandu Valley, average wintertime concentrations of isoprene in Kathmandu were observed to be above 1 ppb (see Fig. 5). To emphasise that the daytime isoprene concentrations were primarily controlled by biogenic emissions, we show realtime data from a day (18 January 2013) when clear covariation of the daytime isoprene concentrations occurred with changes in the solar radiation (Fig. 8b).

High values of isoprene were generally observed from the western and northern sectors (north-north-east where Nil Barahi jungle and Gokarna reserve forest are located) and at appreciable wind speeds $\left(>3 \mathrm{~m} \mathrm{~s}^{-1}\right)$. The advection of air across the valley in the afternoon as they flow through the mountain passes from west to east due to the high-speed westerly winds has been previously described by Panday and Prinn (2009). The forest areas on the mountain slopes appear to contribute to the high ambient isoprene concentrations measured during the afternoon hours. The average daytime (08:00-17:00 LT) isoprene concentrations observed during SusKat-ABC campaign (1.35 ppb) are comparable to the concentrations measured in south-east Asian tropical rainforest sites (Bryan et al., 2012; Jones et al., 2011). As mentioned in the site description section, the forested areas contained tree species like oak and Melia azedarach which have significant isoprene emission potentials $\left(350 \mu \mathrm{g} \mathrm{g}^{-1} \mathrm{dry}\right.$ leaf $h^{-1}$ and $4.7{\mu g^{-1}}^{-1}$ ry leaf $h^{-1}$ respectively; Simon et al., 2005; Padhy and Varshney, 2005). In Sect. 3.7 we examine the importance of VOCs measured during this study in terms of their $\mathrm{OH}$ reactivity contributions and ozone formation potential.

\subsection{OH reactivity and ozone production potential of VOCs}

The oxidation of VOCs (and consequently their removal rate) depends on the reactivity of VOCs with both ozone and hydroxyl radicals during daytime and the nitrate radical during nighttime. For most of the VOCs reported in this work and the typical maximum ozone concentrations observed during winter in the Kathmandu Valley $(\sim 60-70 \mathrm{ppb}$; Putero et al., 2015), the daytime oxidation with hydroxyl radicals is much faster relative to daytime oxidation with ozone and nighttime oxidation with nitrate radicals as $k_{\mathrm{VOC}+\mathrm{OH}}>$ $k_{\mathrm{VOC}+\mathrm{NO}_{3}}>10^{3}-10^{10} \times k_{\mathrm{VOC}+\mathrm{O}_{3}}$ (Atkinson et al., 2006; http://kinetics.nist.gov/kinetics). For dimethyl sulfide, nighttime oxidation with nitrate radical $\left(\mathrm{NO}_{3}\right)$ can be as important as daytime oxidation with $\mathrm{OH}$ as $k_{\mathrm{DMS}}+\mathrm{NO}_{3} \approx k_{\mathrm{DMS}}+\mathrm{OH}$ $\left(k_{\mathrm{DMS}}+\mathrm{NO}_{3}\right.$ and $k_{\mathrm{DMS}}+\mathrm{OH}$ are $1.1 \times 10^{-12}$ and $5.1 \times$ $10^{-12} \mathrm{~cm}^{3} \mathrm{molec}^{-1} \mathrm{~s}^{-1}$ respectively at $\left.T=281.8 \mathrm{~K}\right)$. The hydroxyl radical reactivity of an air mass reflects the total reactive pollutant loading of the air mass and can be used to infer its ozone formation potential (Sinha et al., 2012). While direct total $\mathrm{OH}$ reactivity measurements were not performed during the SusKat-ABC campaign, it is still instructive to examine the diel profile of the $\mathrm{OH}$ reactivity due to the suite of measured VOCs and assess the relative contributions of individual VOCs. For this analysis, we considered 33 out of the 37 species that were observed at average ambient concentrations greater than $200 \mathrm{ppt}$, for which the rate coefficients with the hydroxyl radical are known. Thus, out of the 37 species, four - the nitronium ion $(m / z=45.990)$, isocyanic acid and assorted hydrocarbons detected at $m / z$ ratios of 83.085 and 97.102 - were excluded from this analysis.

The total VOC OH reactivity was calculated as follows (Sinha et al., 2012):

total $\mathrm{VOC} \mathrm{OH}$ reactivity $=\sum k_{\mathrm{VOC}_{i}+\mathrm{OH}}\left[\mathrm{VOC}_{i}\right]$,

where $k_{\mathrm{VOC}_{i}+\mathrm{OH}}$ is the first-order rate coefficient for the reaction of $\mathrm{VOC}_{i}$ with $\mathrm{OH}$ radicals and $\left[\mathrm{VOC}_{i}\right]$ is the measured concentration of $\mathrm{VOC}_{i}$. The rate coefficients were taken from Atkinson et al. (2006) and from the NIST chemical kinetics database (kinetics.nist.gov/kinetics) and Barnes et al. (2010) when they were unavailable in Atkinson et al. (2006).

Figure 9 shows the diel profile of the average sum of VOC $\mathrm{OH}$ reactivity due to 33 ambient VOCs, along with the diel profiles of the hourly averaged $\mathrm{OH}$ reactivity due to the top three contributors. The grey shaded region in Fig. 9 represents the 10th and 90th percentiles of the sum of VOC $\mathrm{OH}$ reactivities due to the 33 ambient VOCs. The average diel profile is bimodal in nature with peaks of ca. $21 \mathrm{~s}^{-1}$ at 09:00 LT and ca. $13 \mathrm{~s}^{-1}$ at 18:00 LT. Interestingly, the 


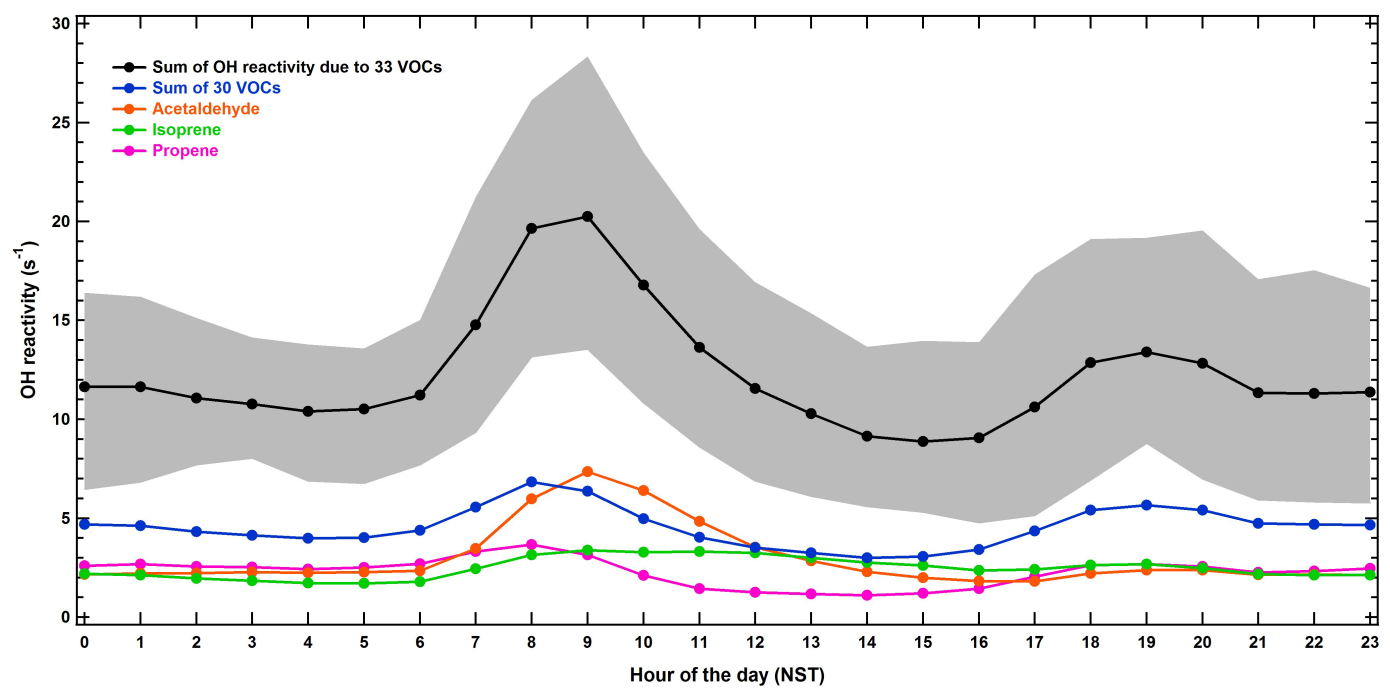

Figure 9. Diel profiles of the calculated total VOC OH reactivity (with 10th and 90th percentile contributions represented by the grey shaded region) and the major VOC contributors.

nighttime value (22:00-06:00 LT) remains rather constant at ca. $12 \mathrm{~s}^{-1}$. The top three contributing compounds to the total calculated VOC OH reactivity due to all 33 compounds were acetaldehyde $(24.0 \%)>$ isoprene $(20.2 \%)>$ propene $(18.7 \%)$. These three VOCs collectively accounted for ca. $63 \%$ of the campaign averaged total $\mathrm{VOC} \mathrm{OH}$ reactivity of $12.3 \mathrm{~s}^{-1}$. Table $\mathrm{S} 3$ in the Supplement lists the top $10 \mathrm{VOC}$ contributors to the total $\mathrm{VOC} \mathrm{OH}$ reactivity, many of which are emitted strongly from biomass combustion sources. The influence of south-easterly winds advecting primary emissions from biomass co-fired brick kilns in the morning hours is clearly discernible on the ambient $\mathrm{OH}$ reactivity profile.

For quantifying the importance of $\mathrm{VOC}$ and $\mathrm{NO}_{x}$ controls on the ozone production efficiency in the Kathmandu Valley, simultaneous measurements of both $\mathrm{VOCs}$ and $\mathrm{NO}_{x}$ are necessary. The relative ozone formation potential of VOCs can be derived as described by the following equation (Sinha et al., 2012):

ozone production potential $=\left(\sum k_{\left(\mathrm{VOC}_{i}+\mathrm{OH}\right)}\left[\mathrm{VOC}_{i}\right]\right)$

$\times[\mathrm{OH}] \times n$.

For the ozone production potential calculation, the average hydroxyl radical concentration was assumed to be $[\mathrm{OH}]=1 \times 10^{6}$ molecules $\mathrm{cm}^{-3}$ with $n=2$ and only data pertaining to the mid-daytime period were considered (11:0014:00 LT). The temporal context of the analyses performed using VOC data acquired during the afternoon (11:0014:00 LT: the period for which ozone production potentials were calculated) is quite relevant considering the recently published work of Putero et al. (2015), which highlighted that hourly average concentrations of $>60 \mathrm{ppb}$ are often observed during winter afternoons in the Kathmandu Valley (refer to Fig. 9 of Putero et al., 2015). This shows that regional photochemistry is strong even during winter and formation of secondary pollutants contributes to hourly ozone concentrations in excess of $60 \mathrm{ppb}$. Figure 10a and b summarise the results in the form of pie charts for period 1 (when most brick kilns were inactive but daytime biogenic emissions of isoprene dominated) and period 2 (when brick kilns became operational, isoprene emissions were lower and biomass burning was stronger in intensity). To ascertain the contribution of different chemical classes of compounds (e.g. OVOCs, benzenoids, isoprene) to total ozone formation potential, the 33 compounds were further divided into 5 chemical subgroups as shown. It was found that for both period 1 and period 2, oxygenated VOCs and isoprene collectively accounted for more than $68 \%$ ( $72 \%$ for period 1 and $68 \%$ for period 2 ) of the total ozone production potential. This is not surprising given that acetaldehyde and isoprene were among the highest contributors to the $\mathrm{VOC} \mathrm{OH}$ reactivity. This analysis puts in perspective the relative ranking of individual VOCs and classes of VOCs to the ozone production potential in the Kathmandu Valley for potential mitigation efforts.

\subsection{SOA formation potential of VOCs in the Kathmandu Valley}

Apart from ground-level ozone formation, SOA can also be formed as a result of atmospheric oxidation of VOCs. The 71 detected ions collectively summed up to a total mass concentration of $\sim 160.4 \mu_{\mathrm{g} \mathrm{m}}^{-3}$, out of which the 37 identified ions and VOCs reported in this work, accounted for $\sim 139.1 \mu \mathrm{g} \mathrm{m}^{-3}$ (or $86.7 \%$ ). Pudasainee et al. (2006) previously reported $\mathrm{NO}_{x}$-rich conditions in the Kathmandu Valley and based on the SOA yields reported in the literature (e.g. $5-10 \%$ for toluene and xylenes and $\sim 28 \%$ for benzene; $\mathrm{Ng}$ et al., 2007) and the ambient concentrations of these 

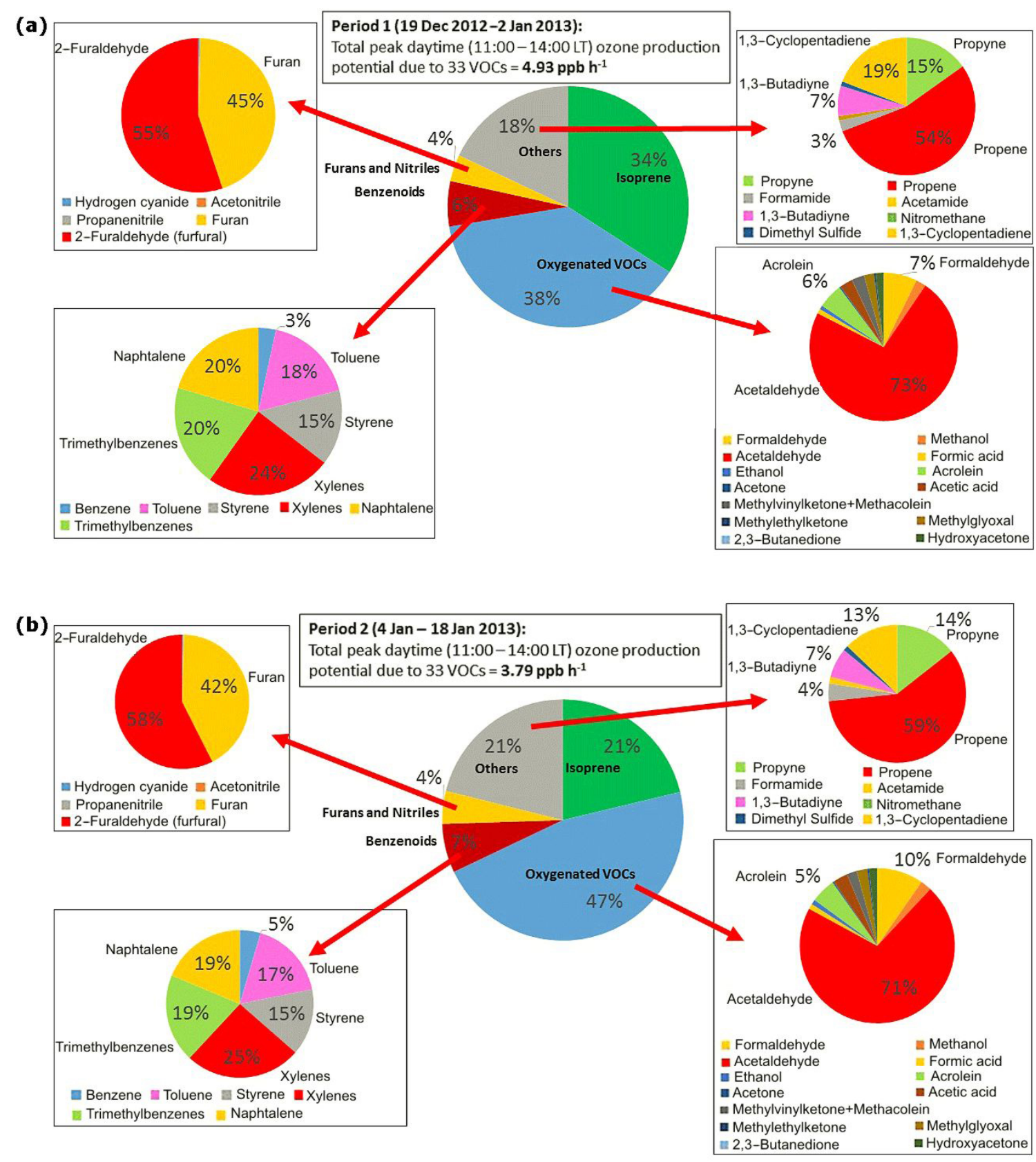

Figure 10. Pie charts showing contribution of different class of compounds to total ozone formation potential for (a) period 1 (19 December 2012-2 January 2013) and (b) period 2 (4-18 January 2013).

VOCs measured during the period of study, we estimate the order of SOA production potential for these VOCs to be benzene $>$ naphthalene $>$ toluene $>$ xylenes $>$ monoterpenes $>$ trimethylbenzenes $>$ styrene $>$ isoprene. Although the average ambient concentrations of the sum of monoterpenes $(0.17 \pm 0.16 \mathrm{ppb})$ were below $200 \mathrm{ppt}$, it contributed significantly to the total SOA formation due to its higher SOA yield under high $\mathrm{NO}_{x}$ conditions (Lee et al., 2006).

\subsection{VOCs with direct health implications}

Several VOCs detected in the Kathmandu Valley have consequences for human health, often at concentrations of documented concern. Benzene and formaldehyde are considered human carcinogens (groups A and B1 respectively) by WHO (2010). Among other rarely quantified ambient VOCs, shortchain amides, such as formamide and acetamide, can have several health effects (Ge et al., 2011). While acetamide is considered a Group 2B human carcinogen by the Interna- 
tional Agency for Research on Cancer http://www.iarc.fr/), nitromethane is also a Group 2B carcinogen and has been reported as a possible carcinogen to humans (Inomata et al., 2014). Some gases can result in formation of toxic secondary VOCs. For example, naphthalene is not considered to be a human carcinogen, but it can form mutagenic nitronaphthalenes by $\mathrm{OH}$ and $\mathrm{NO}_{3}$ initiated reactions (Sasaki et al., 1997; Zhang et al., 2012). Atmospheric oxidation of amide compounds such as formamide and acetamide with hydroxyl radicals also contributes to the formation of isocyanic acid (Barnes et al., 2010). Ambient isocyanic acid was present at exposure levels of documented concern that can enhance human health risks for cataracts, cardiovascular diseases and rheumatoid arthritis via protein carbamylation (Wang et al., 2007; Roberts et al., 2011). Thus long-term monitoring of these gases (isocyanic acid, formamide, acetamide, benzene, formaldehyde, nitromethane, naphthalene), which can cause adverse effects upon sustained exposure even at concentrations of few ppb, is warranted to establish exposure and assessing health risks due to these VOCs in the Kathmandu Valley.

\section{Conclusions}

This study has comprehensively characterized the chemical composition of air in the Kathmandu Valley in terms of speciated volatile organic compounds during the SusKat$\mathrm{ABC}$ wintertime campaign. The measurements performed at high time resolution (every minute) and high mass resolution $(m / \Delta m>4200)$ enabled us to identify a multitude of compounds based on their monoisotopic masses and hence exact molecular formula. Novel insights could be acquired regarding chemical processes related to ozone and secondary organic aerosol formation in a complex chemical environment affected by mountain meteorology and both anthropogenic and biogenic sources (even in winter).

A total of 71 ion peaks were observed in the mass spectra of PTR-TOF-MS that were above the detection limit of the instrument. Out of these, 37 species that had average ambient concentrations greater than 200 ppt during the campaign could be identified with reasonable confidence based on (1) spectral characteristics observed at a particular $\mathrm{m} / \mathrm{z}$ in a $0.005 \mathrm{amu}$ bin relative to the ion peak, (2) ambient diel profiles and (3) correlation with specific emission tracer molecules such as acetonitrile (a biomass burning tracer). A 200 ppt cut off was also chosen as an additional quality control measure so as to ensure attribution of ion peaks in the mass spectra only to the compounds present in the ambient air and not due to instrumental reasons. Among these 37 species, 8 contained nitrogen, 15 contained oxygen, 13 were hydrocarbons and 1 contained sulfur. Based on chemical signatures of tracer compounds such as acetonitrile and isoprene, two periods with contrasting emission influences were identified during the campaign and investigated in de- tail. Period 1 (19 December 2012-2 January 2013) was characterized by high daytime biogenic emissions of isoprene (average isoprene concentrations in period 1 and period 2 were 1.66 and $0.97 \mathrm{ppb}$ respectively) and the absence of operational brick kilns (and hence their emissions); period 2 (4 January 2013-18 January 2013) was marked by high acetonitrile (average concentration during this Period was $1.34 \mathrm{ppb})$, benzene (3.46 ppb) and isocyanic acid (1.03 ppb) due to emissions from the biomass co-fired brick kilns and other biofuel/biomass burning activities. A clear distinction of isoprene from furan, which had distinct emission profiles, highlighted the importance of deploying a PTR-TOF-MS for VOC measurements in the Kathmandu Valley.

Two "new" compounds which have not been reported in any previous ambient study, namely formamide $\left(\mathrm{CH}_{3} \mathrm{NO}\right.$; protonated $m / z=46.029$; campaign average $0.76 \mathrm{ppb}$ ) and acetamide $\left(\mathrm{C}_{2} \mathrm{H}_{5} \mathrm{NO}\right.$; protonated $\mathrm{m} / z=60.051$; campaign average $0.39 \mathrm{ppb}$ ), which are involved in photochemical formation of isocyanic acid, were also detected. The average total reactive carbon (sum of the average mixing ratios of all the 37 species reported in this study) was $175.8 \mathrm{ppbC}$ to which propyne, acetaldehyde, benzene, acetic acid, acetone, propene and toluene collectively contributed more than $60 \%$. Isoprene concentrations as high as $3 \mathrm{ppb}$ were observed frequently during the daytime in the early part of the campaign (December 2012) and could be traced to biogenic emissions from vegetation in fetch regions upwind of the site.

The concentration ranking in the average VOC mixing ratios during our wintertime deployment was acetaldehyde $(8.8 \mathrm{ppb})>$ methanol $(7.4 \mathrm{ppb})>$ acetone + propanal $(4.2 \mathrm{ppb})>$ benzene $(2.7 \mathrm{ppb})>$ toluene $(1.5 \mathrm{ppb})>$ isoprene $(1.1 \mathrm{ppb})>$ acetonitrile $(1.1 \mathrm{ppb})>\mathrm{C} 8$-aromatics $(\sim 1 \mathrm{ppb})>$ furan $(\sim 0.5 \mathrm{ppb})>$ C 9 -aromatics $(0.4 \mathrm{ppb})$. The results suggest that the emission sources of oxygenated and aromatic VOCs in the Kathmandu Valley are different compared to several cities such as Paris and London, likely due to the emissions from biomass co-fired brick kilns, open burning of biomass (e.g. garden waste, agro-residue burning and garbage burning) and extensive use of diesel generators. In comparison to wintertime mixing ratios reported from several sites elsewhere in the world, the mixing ratios of acetaldehyde ( $\sim 9 \mathrm{ppb})$, acetonitrile $(\sim 1 \mathrm{ppb})$ and isoprene $(\sim$ $1 \mathrm{ppb})$ in the Kathmandu Valley are among the highest measured anywhere in the world. The major sources of propyne, propene, benzene and propanenitrile in the valley appeared to be biomass burning as concentrations of all these compounds correlated well with the biomass burning tracer acetonitrile $\left(r^{2}>0.7\right)$ and had diel emission profiles similar to that of acetonitrile.

The top three contributing compounds to the total calculated VOC $\mathrm{OH}$ reactivity due to 33 compounds were acetaldehyde $(24.0 \%)$, isoprene $(20.2 \%)$ and propene $(18.7 \%)$, which collectively accounted for ca. $63 \%$ of the campaign averaged total VOC OH reactivity of $12.3 \mathrm{~s}^{-1}$. Oxygenated VOCs and isoprene collectively accounted for 
more than $68 \%$ ( $72 \%$ for period 1 and $68 \%$ for period 2 ) of the total ozone production potential. Based on known SOA yields of compounds and the ambient concentrations measured in the Kathmandu Valley, it was estimated that the relative SOA production potential of VOCs was in the following order: benzene $>$ naphthalene $>$ toluene $>$ xylenes $>$ monoterpenes $>$ trimethylbenzenes $>$ styrene $>$ isoprene. Several VOCs known to increase health risks of cancer, cataract and pulmonary diseases were detected in the ambient air. The synergistic effect of these VOCs on air toxicity is difficult to quantify but likely significant. The prominent ones were isocyanic acid, formamide, acetamide, naphthalene and nitromethane, for which this study presents the first measurements in ambient air from South Asia along with benzene, a human carcinogen.

Although, like all urban environments, the contribution of traffic sources to ambient VOCs is significant in the Kathmandu Valley, another anthropogenic source which occupies central importance in the Kathmandu Valley (due to inefficient combustion) is the biomass co-fired brick kiln. While we did not measure particulate matter emissions from the biomass co-fired brick kilns in the Kathmandu Valley during our deployment, previous studies by Pariyar et al. (2013) and Raut (2003) have reported and documented massive increases in $\mathrm{PM}_{10}$ and TSP for periods marked by the operation of the brick kilns relative to periods when they were not operational. The study conducted by Clean Energy Nepal (Raut, 2003) showed that $8 \mathrm{~h}$ averaged concentrations of air pollutants such as TSP, $\mathrm{PM}_{10}, \mathrm{SO}_{2}$ and $\mathrm{NO}_{x}$ were 3 times higher during the brick kiln operating period relative to the period they were not operational at the same location. The mass concentration of $\mathrm{PM}_{10}$ increased from 218 to $603 \mu \mathrm{g} \mathrm{m}{ }^{-3}$ while TSP increased from 265 to $634 \mu \mathrm{g} \mathrm{m}^{-3}$. Note that these were primarily FCBTKs, similar to the ones that impacted our measurements. The FCBTKs are an old and inefficient technology which have been banned even in their place of origin, India, but continue to dominate the Kathmandu Valley landscape. Thus a major conclusion of this study is that replacing the existing brick kiln technology with cleaner and more efficient brick kiln technology would aid air pollution mitigation efforts significantly. While much has been learnt about wintertime VOC speciation in Kathmandu from this study, and the first comprehensive data set has been acquired, long-term measurements and further field intensives are required.

Future studies need to focus on what happens in the valley on seasonal and interannual timescales. Of particular interest would be assessing the concentrations of isoprene and acetaldehyde in summer and their atmospheric chemistry. Assessment of source specific emission ratios (inter VOC) for the major sources (brick kilns, diesel generator exhaust, leaf litter fires, etc.) and improvement of existing emission inventories using the in situ data should be undertaken. The comparison and estimation of the fraction of isoprene from vegetation and combustion will also be presented in a companion paper (Sarkar et al., 2016) in which source apportionment of
VOCs will be performed using positive matrix factorisation model. Comprehensive air quality and policy recommendations based on all the data acquired during the SusKat-ABC study and from other sites in the Kathmandu Valley will be summarised in future submissions to this Special Issue (Rupakheti et al., 2016; Panday et al., 2016).

\section{The Supplement related to this article is available online at doi:10.5194/acp-16-3979-2016-supplement.}

Acknowledgements. Chinmoy Sarkar, Vinod Kumar and Vinayak Sinha acknowledge the support extended by the Founding Director of IISER Mohali, N. Sathyamurthy to enable participation of the IISER Mohali team in the SusKat-ABC campaign. Chinmoy Sarkar and Vinod Kumar acknowledge the Ministry of Human Resources and Development (MHRD), India, and Department of Science and Technology (INSPIRE program), India, respectively for their PhD fellowships. We thank Joost de Gouw and Rui Li for helpful discussions regarding detection of isocyanic acid using the PTR-TOF-MS technique and Achim Edtbauer and Ionicon Analytik for their support. Bob Yokelson is thanked for input regarding detection of ketene and acetic acid. We thank the anonymous reviewer 1 and the editor for their extremely helpful suggestions. We dedicate this work to the memory of the victims of the devastating earthquake that hit Nepal in 2015.

All the data reported in this article can be obtained from the corresponding author by sending an email to vsinha@iisermohali.ac.in.

Edited by: J. Roberts

\section{References}

Akagi, S. K., Yokelson, R. J., Wiedinmyer, C., Alvarado, M. J., Reid, J. S., Karl, T., Crounse, J. D., and Wennberg, P. O.: Emission factors for open and domestic biomass burning for use in atmospheric models, Atmos. Chem. Phys., 11, 4039-4072, doi:10.5194/acp-11-4039-2011, 2011.

Akagi, S. K., Yokelson, R. J., Burling, I. R., Meinardi, S., Simpson, I., Blake, D. R., McMeeking, G. R., Sullivan, A., Lee, T., Kreidenweis, S., Urbanski, S., Reardon, J., Griffith, D. W. T., Johnson, T. J., and Weise, D. R.: Measurements of reactive trace gases and variable $\mathrm{O}_{3}$ formation rates in some South Carolina biomass burning plumes, Atmos. Chem. Phys., 13, 1141-1165, doi:10.5194/acp-13-1141-2013, 2013.

Al-Naiema, I., Estillore, A. D., Mudunkotuwa, I. A., Grassian, V. H., and Stone, E. A.: Impacts of co-firing biomass on emissions of particulate matter to the atmosphere, Fuel, 162, 111-120, doi:10.1016/j.fuel.2015.08.054, 2015.

Andreae, M. O. and Merlet, P.: Emission of trace gases and aerosols from biomass burning, Global Biogeochem. Cy., 15, 955-966, doi:10.1029/2000gb001382, 2001.

Andreae, M. O. and Raemdonck, H.: Dimethyl sulfide in the surface ocean and the marine atmosphere - a global view, Science, 221, 744-747, 1983. 
Aoki, N., Inomata, S., and Tanimoto, H.: Detection of C1C5 alkyl nitrates by proton transfer reaction time-of-flight mass spectrometry, Int. J. Mass Spectrom., 263, 12-21, doi:10.1016/j.ijms.2006.11.018, 2007.

Atkinson, R.: Atmospheric chemistry of VOCs and $\mathrm{NO}_{x}$, Atmos. Environ., 34, 2063-2101, doi:10.1016/S1352-2310(99)00460-4, 2000

Atkinson, R., Baulch, D. L., Cox, R. A., Crowley, J. N., Hampson, R. F., Hynes, R. G., Jenkin, M. E., Rossi, M. J., Troe, J., and IUPAC Subcommittee: Evaluated kinetic and photochemical data for atmospheric chemistry: Volume II - gas phase reactions of organic species, Atmos. Chem. Phys., 6, 3625-4055, doi:10.5194/acp-6-3625-2006, 2006.

Barletta, B., Meinardi, S., Simpson, I. J., Khwaja, H. A., Blake, D. R., and Rowland, F. S.: Mixing ratios of volatile organic compounds (VOCs) in the atmosphere of Karachi, Pakistan, Atmos. Environ., 36, 3429-3443, doi:10.1016/S13522310(02)00302-3, 2002.

Barletta, B., Meinardi, S., Sherwood Rowland, F., Chan, C. Y., Wang, X., Zou, S., Yin Chan, L., and Blake, D. R.: Volatile organic compounds in 43 Chinese cities, Atmos. Environ., 39, 5979-5990, doi:10.1016/j.atmosenv.2005.06.029, 2005.

Barnes, I., Solignac, G., Mellouki, A., and Becker, K. H.: Aspects of the atmospheric chemistry of amides, Chem. Phys. Chem., 11, 3844-3857, doi:10.1002/cphc.201000374, 2010.

Borbon, A., Fontaine, H., Veillerot, M., Locoge, N., Galloo, J. C., and Guillermo, R.: An investigation into the traffic-related fraction of isoprene at an urban location, Atmos. Environ., 35, 37493760, doi:10.1016/S1352-2310(01)00170-4, 2001.

Bryan, A. M., Bertman, S. B., Carroll, M. A., Dusanter, S., Edwards, G. D., Forkel, R., Griffith, S., Guenther, A. B., Hansen, R. F., Helmig, D., Jobson, B. T., Keutsch, F. N., Lefer, B. L., Pressley, S. N., Shepson, P. B., Stevens, P. S., and Steiner, A. L.: In-canopy gas-phase chemistry during CABINEX 2009: sensitivity of a 1-D canopy model to vertical mixing and isoprene chemistry, Atmos. Chem. Phys., 12, 8829-8849, doi:10.5194/acp-12-8829-2012, 2012.

Central Bureau of Statistics: Nepal Population and Housing Census Report, National Planning Commission Secretariat, Government of Nepal, Kathmandu, 2011, 1-262, 2011.

Chandra, B. P., and Sinha, V.: Contribution of post-harvest agricultural paddy residue fires in the N.W. Indo-Gangetic Plain to ambient carcinogenic benzenoids, toxic isocyanic acid and carbon monoxide, Environ. Int., 88, 187-197, doi:10.1016/j.envint.2015.12.025, 2016.

Christian, T. J., Kleiss, B., Yokelson, R. J., Holzinger, R., Crutzen, P. J., Hao, W. M., Saharjo, B. H., and Ward, D. E.: Comprehensive laboratory measurements of biomass-burning emissions: 1. Emissions from Indonesian, African, and other fuels, J. Geophys. Res.-Atmos., 108, 4719, doi:10.1029/2003jd003704, 2003.

Davidson, C. I., Lin, S. F., Osborn, J. F., Pandey, M. R., Rasmussen, R. A., and Khalil, M. A. K.: Indoor and outdoor air pollution in the Himalayas, Environ. Sci. Technol., 20, 561-567, doi:10.1021/es00148a003, 1986.

de Foy, B., Varela, J. R., Molina, L. T., and Molina, M. J.: Rapid ventilation of the Mexico City basin and regional fate of the urban plume, Atmos. Chem. Phys., 6, 2321-2335, doi:10.5194/acp-6-2321-2006, 2006. de Gouw, J. and Warneke, C.: Measurements of volatile organic compounds in the earth's atmosphere using proton-transferreaction mass spectrometry, Mass Spectrom. Rev., 26, 223-257, doi:10.1002/mas.20119, 2007.

de Gouw, J. A., Goldan, P. D., Warneke, C., Kuster, W. C., Roberts, J. M., Marchewka, M., Bertman, S. B., Pszenny, A. A. P., and Keene, W. C.: Validation of proton transfer reaction-mass spectrometry (PTR-MS) measurements of gas-phase organic compounds in the atmosphere during the New England Air Quality Study (NEAQS) in 2002, J. Geophys. Res.-Atmos., 108, 4682, doi:10.1029/2003jd003863, 2003.

Department of Plant Resources, Nepal: Bulletin of Department of Plant Resources, Nepal 37, Ministry of Forests and Soil Conservation, Kathmandu, 1-122, 2015.

Dolgorouky, C., Gros, V., Sarda-Esteve, R., Sinha, V., Williams, J., Marchand, N., Sauvage, S., Poulain, L., Sciare, J., and Bonsang, B.: Total $\mathrm{OH}$ reactivity measurements in Paris during the 2010 MEGAPOLI winter campaign, Atmos. Chem. Phys., 12, 9593-9612, doi:10.5194/acp-12-9593-2012, 2012.

Filella, I. and Peńuelas, J.: Daily, weekly, and seasonal time courses of VOC concentrations in a semi-urban area near Barcelona, Atmos. Environ., 40, 7752-7769, doi:10.1016/j.atmosenv.2006.08.002, 2006.

Ge, X., Wexler, A. S., and Clegg, S. L.: Atmospheric amines - Part I. A review, Atmos. Environ., 45, 524-546, doi:10.1016/j.atmosenv.2010.10.012, 2011.

Geron, C., Harley, P., and Guenther, A.: Isoprene emission capacity for US tree species, Atmos. Environ., 35, 3341-3352, doi:10.1016/S1352-2310(00)00407-6, 2001.

Gilman, J. B., Lerner, B. M., Kuster, W. C., Goldan, P. D., Warneke, C., Veres, P. R., Roberts, J. M., de Gouw, J. A., Burling, I. R., and Yokelson, R. J.: Biomass burning emissions and potential air quality impacts of volatile organic compounds and other trace gases from fuels common in the US, Atmos. Chem. Phys., 15, 13915-13938, doi:10.5194/acp-15-13915-2015, 2015.

Grosjean, D., Grosjean, E., and Williams, E. L.: Atmospheric chemistry of olefins: a product study of the ozone-alkene reaction with cyclohexane added to scavenge hydroxyl radical, Environ. Sci. Technol., 28, 186-196, doi:10.1021/es00050a026, 1994.

Grosjean, E., Rasmussen, R. A., and Grosjean, D.: Ambient levels of gas phase pollutants in Porto Alegre, Brazil, Atmos. Environ., 32, 3371-3379, doi:10.1016/S1352-2310(98)00007-7, 1998.

Guenther, A., Karl, T., Harley, P., Wiedinmyer, C., Palmer, P. I., and Geron, C.: Estimates of global terrestrial isoprene emissions using MEGAN (Model of Emissions of Gases and Aerosols from Nature), Atmos. Chem. Phys., 6, 3181-3210, doi:10.5194/acp-63181-2006, 2006.

Guo, H., So, K. L., Simpson, I. J., Barletta, B., Meinardi, S., and Blake, D. R.: C1-C8 volatile organic compounds in the atmosphere of Hong Kong: overview of atmospheric processing and source apportionment, Atmos. Environ., 41, 1456-1472, doi:10.1016/j.atmosenv.2006.10.011, 2007.

Gurung, A. and Bell, M. L.: Exposure to airborne particulate matter in Kathmandu Valley, Nepal, J. Expos. Sci. Environ. Epidemiol., 22, 235-242, 2012.

Hao, W. M., Ward, D. E., Olbu, G., and Baker, S. P.: Emissions of $\mathrm{CO}_{2}, \mathrm{CO}$, and hydrocarbons from fires in diverse African savanna ecosystems, J. Geophys. Res.-Atmos., 101, 23577-23584, 1996. 
Hellèn, H., Tykkä, T., and Hakola, H.: Importance of monoterpenes and isoprene in urban air in northern Europe, Atmos. Environ., 59, 59-66, doi:10.1016/j.atmosenv.2012.04.049, 2012.

Henze, D. K., Seinfeld, J. H., Ng, N. L., Kroll, J. H., Fu, T.-M., Jacob, D. J., and Heald, C. L.: Global modeling of secondary organic aerosol formation from aromatic hydrocarbons: highvs. low-yield pathways, Atmos. Chem. Phys., 8, 2405-2420, doi:10.5194/acp-8-2405-2008, 2008.

Holzinger, R., Warneke, C., Hansel, A., Jordan, A., Lindinger, W., Scharffe, D. H., Schade, G., and Crutzen, P. J.: Biomass burning as a source of formaldehyde, acetaldehyde, methanol, acetone, acetonitrile, and hydrogen cyanide, Geophys. Res. Lett., 26, 1161-1164, doi:10.1029/1999g1900156, 1999.

Inomata, S., Tanimoto, H., Fujitani, Y., Sekimoto, K., Sato, K., Fushimi, A., Yamada, H., Hori, S., Kumazawa, Y., Shimono, A., and Hikida, T.: On-line measurements of gaseous nitro-organic compounds in diesel vehicle exhaust by protontransfer-reaction mass spectrometry, Atmos. Environ., 73, 195203, doi:10.1016/j.atmosenv.2013.03.035, 2013.

Inomata, S., Fujitani, Y., Fushimi, A., Tanimoto, H., Sekimoto, K., and Yamada, H.: Field measurement of nitromethane from automotive emissions at a busy intersection using proton-transferreaction mass spectrometry, Atmos. Environ., 96, 301-309, doi:10.1016/j.atmosenv.2014.07.058, 2014.

IPCC: Impacts, Adaptation and Vulnerability: Working Group II Contribution to the Intergovernmental Panel on Climate Change: Fifth Assessment Report: Summary for Policymakers, Intergovernmental Panel on Climate Change. Working Group Impacts, Cambridge University Press, Cambridge, UK and New York, NY, USA, 1-32, 2013.

Jardine, K., Yañez-Serrano, A. M., Williams, J., Kunert, N., Jardine, A., Taylor, T., Abrell, L., Artaxo, P., Guenther, A., Hewitt, C. N., House, E., Florentino, A. P., Manzi, A., Higuchi, N., Kesselmeier, J., Behrendt, T., Veres, P. R., Derstroff, B., Fuentes, J. D., Martin, S. T., and Andreae, M. O.: Dimethyl sulfide in the Amazon rain forest, Global Biogeochem. Cy., 29, 1932, doi:10.1002/2014gb004969, 2015.

Jones, C. E., Hopkins, J. R., and Lewis, A. C.: In situ measurements of isoprene and monoterpenes within a south-east Asian tropical rainforest, Atmos. Chem. Phys., 11, 6971-6984, doi:10.5194/acp-11-6971-2011, 2011.

Jordan, A., Haidacher, S., Hanel, G., Hartungen, E., Märk, L., Seehauser, H., Schottkowsky, R., Sulzer, P., and Märk, T. D.: A high resolution and high sensitivity proton-transfer-reaction time-offlight mass spectrometer (PTR-TOF-MS), Int. J. Mass Spectrom., 286, 122-128, doi:10.1016/j.ijms.2009.07.005, 2009.

Karl, T., Jobson, T., Kuster, W. C., Williams, E., Stutz, J., Shetter, R., Hall, S. R., Goldan, P., Fehsenfeld, F., and Lindinger, W.: Use of proton-transfer-reaction mass spectrometry to characterize volatile organic compound sources at the La Porte super site during the Texas Air Quality Study 2000, J. Geophys. Res.Atmos., 108, 4508, doi:10.1029/2002jd003333, 2003.

Karl, T. G., Christian, T. J., Yokelson, R. J., Artaxo, P., Hao, W. M., and Guenther, A.: The Tropical Forest and Fire Emissions Experiment: method evaluation of volatile organic compound emissions measured by PTR-MS, FTIR, and GC from tropical biomass burning, Atmos. Chem. Phys., 7, 5883-5897, doi:10.5194/acp-7-5883-2007, 2007.
Kesselmeier, J., Bode, K., Hofmann, U., Müller, H., Schäfer, L., Wolf, A., Ciccioli, P., Brancaleoni, E., Cecinato, A., Frattoni, M., Foster, P., Ferrari, C., Jacob, V., Fugit, J. L., Dutaur, L., Simon, V., and Torres, L.: Emission of short chained organic acids, aldehydes and monoterpenes from Quercus ilex L., and Pinus pinea L. in relation to physiological activities, carbon budget and emission algorithms, Atmos. Environ., 31, 119-133, doi:10.1016/S1352-2310(97)00079-4, 1997.

Kesselmeier, J. and Staudt, M.: Biogenic Volatile Organic Compounds (VOC): an overview on emission, physiology and ecology, J. Atmos. Chem., 33, 23-88, doi:10.1023/a:1006127516791, 1999.

Kitada, T. and Regmi, R. P.: Dynamics of air pollution transport in late wintertime over Kathmandu Valley, Nepal: as revealed with numerical simulation, J. Appl. Meteorol., 42, 1770-1798, doi:10.1175/1520-0450(2003)042<1770:DOAPTI> 2.0.CO;2, 2003.

Kumar, V. and Sinha, V.: VOC-OHM: A new technique for rapid measurements of ambient total $\mathrm{OH}$ reactivity and volatile organic compounds using a single proton transfer reaction mass spectrometer, Int. J. Mass Spectrom., 374, 55-63, doi:10.1016/j.ijms.2014.10.012, 2014.

Langford, B., Nemitz, E., House, E., Phillips, G. J., Famulari, D., Davison, B., Hopkins, J. R., Lewis, A. C., and Hewitt, C. N.: Fluxes and concentrations of volatile organic compounds above central London, UK, Atmos. Chem. Phys., 10, 627-645, doi:10.5194/acp-10-627-2010, 2010.

Larssen, S., F. Gram, I. Haugsbakk, J. Huib, X. Olsthoorn, A. S. Giri, R. Shah, M. L. Shrestha, A., and Shrestha, B.: Urban Air Quality Management Strategy in Asia: Kathmandu Valley Report, World Bank, Washington, D.C., USA, 1-173, 1997.

Lee, A., Goldstein, A. H., Kroll, J. H., Ng, N. L., Varutbangkul, V., Flagan, R. C., and Seinfeld, J. H.: Gas-phase products and secondary aerosol yields from the photooxidation of 16 different terpenes, J. Geophys. Res.-Atmos., 111, D17305, doi:10.1029/2006jd007050, 2006.

Lelieveld, J., Dentener, F. J., Peters, W., and Krol, M. C.: On the role of hydroxyl radicals in the self-cleansing capacity of the troposphere, Atmos. Chem. Phys., 4, 2337-2344, doi:10.5194/acp4-2337-2004, 2004.

Lemieux, P. M., Lutes, C. C., and Santoianni, D. A.: Emissions of organic air toxics from open burning: a comprehensive review, Progress in Energy and Combustion Science, 30, 1-32, doi:10.1016/j.pecs.2003.08.001, 2004.

Lindinger, W., Hansel, A., and Jordan, A.: On-line monitoring of volatile organic compounds at pptv levels by means of protontransfer-reaction mass spectrometry (PTR-MS) medical applications, food control and environmental research, Int. J. Mass Spectrom., 173, 191-241, doi:10.1016/s0168-1176(97)00281-4, 1998.

Liu, Ying, Shao, Min, Lu, Sihua, Chang, Chih-chung, Wang, JiaLin, and Chen, Gao: Volatile Organic Compound (VOC) measurements in the Pearl River Delta (PRD) region, China, Atmos. Chem. Phys., 8, 1531-1545, doi:10.5194/acp-8-1531-2008, 2008.

Lockhart, J., Blitz, M. A., Heard, D. E., Seakins, P. W., and Shannon, R. J.: The mechanism of the reaction of $\mathrm{OH}$ with alkynes in the presence of oxygen, J. Phys. Chem. A, 117, 5407-5418, doi:10.1021/jp404233b, 2013. 
Martinez, M., Harder, H., Ren, X., Lesher, R. L., and Brune, W. H.: Measuring atmospheric naphthalene with laser-induced fluorescence, Atmos. Chem. Phys., 4, 563-569, doi:10.5194/acp-4-5632004, 2004.

Millet, D. B., Guenther, A., Siegel, D. A., Nelson, N. B., Singh, H. B., de Gouw, J. A., Warneke, C., Williams, J., Eerdekens, G., Sinha, V., Karl, T., Flocke, F., Apel, E., Riemer, D. D., Palmer, P. I., and Barkley, M.: Global atmospheric budget of acetaldehyde: 3-D model analysis and constraints from in-situ and satellite observations, Atmos. Chem. Phys., 10, 34053425, doi:10.5194/acp-10-3405-2010, 2010.

Molina, L. T., Kolb, C. E., de Foy, B., Lamb, B. K., Brune, W. H., Jimenez, J. L., Ramos-Villegas, R., Sarmiento, J., ParamoFigueroa, V. H., Cardenas, B., Gutierrez-Avedoy, V., and Molina, M. J.: Air quality in North America's most populous city - overview of the MCMA-2003 campaign, Atmos. Chem. Phys., 7, 2447-2473, doi:10.5194/acp-7-2447-2007, 2007.

Müller, M., Graus, M., Ruuskanen, T. M., Schnitzhofer, R., Bamberger, I., Kaser, L., Titzmann, T., Hörtnagl, L., Wohlfahrt, G., Karl, T., and Hansel, A.: First eddy covariance flux measurements by PTR-TOF, Atmos. Meas. Tech., 3, 387-395, doi:10.5194/amt-3-387-2010, 2010.

Nelson, P. F., Li, C. Z., and Ledesma, E.: Formation of HNCO from the rapid pyrolysis of coals, Energy and Fuels, 10, 264265, doi:10.1021/ef950183o, 1996.

Ng, N. L., Chhabra, P. S., Chan, A. W. H., Surratt, J. D., Kroll, J. H., Kwan, A. J., McCabe, D. C., Wennberg, P. O., Sorooshian, A., Murphy, S. M., Dalleska, N. F., Flagan, R. C., and Seinfeld, J. H.: Effect of $\mathrm{NO}_{x}$ level on secondary organic aerosol (SOA) formation from the photooxidation of terpenes, Atmos. Chem. Phys., 7, 5159-5174, doi:10.5194/acp-7-5159-2007, 2007.

Padhy, P. K. and Varshney, C. K.: Emission of volatile organic compounds (VOC) from tropical plant species in India, Chemosphere, 59, 1643-1653, doi:10.1016/j.chemosphere.2005.01.046, 2005.

Panday, A. K. and Prinn, R. G.: Diurnal cycle of air pollution in the Kathmandu Valley, Nepal: observations, J. Geophys. Res.Atmos., 114, D09305, doi:10.1029/2008jd009777, 2009.

Panday, A. K., Prinn, R. G., and Schär, C.: Diurnal cycle of air pollution in the Kathmandu Valley, Nepal: 2. Modeling results, J. Geophys. Res.-Atmos., 114, D21308, doi:10.1029/2008jd009808, 2009.

Panday, A. K., Adhikary, B., Praveen, P. S., Mahata, K. S., and Rupakheti, M.: Meteorology and Air Pollution Transport in the Kathmandu Valley, Nepal, Atmos. Chem. Phys. Discuss., in preparation, 2016.

Pariyar, S. K., Das, T., and Ferdous, T.: Environment and Health Impact for Brick Kilns in Kathmandu Valley, Int. J. Sci. Technol. Res., 2, 184-187, 2013.

Park, J.-H., Goldstein, A. H., Timkovsky, J., Fares, S., Weber, R., Karlik, J., and Holzinger, R.: Eddy covariance emission and deposition flux measurements using proton transfer reaction - time of flight - mass spectrometry (PTR-TOF-MS): comparison with PTR-MS measured vertical gradients and fluxes, Atmos. Chem. Phys., 13, 1439-1456, doi:10.5194/acp-13-1439-2013, 2013.

Pudasainee, D., Sapkota, B., Shrestha, M. L., Kaga, A., Kondo, A., and Inoue, Y.: Ground level ozone concentrations and its association with $\mathrm{NO}_{x}$ and meteorological parameters in
Kathmandu Valley, Nepal, Atmos. Environ., 40, 8081-8087, doi:10.1016/j.atmosenv.2006.07.011, 2006.

Putero, D., Cristofanelli, P., Marinoni, A., Adhikary, B., Duchi, R., Shrestha, S. D., Verza, G. P., Landi, T. C., Calzolari, F., Busetto, M., Agrillo, G., Biancofiore, F., Di Carlo, P., Panday, A. K., Rupakheti, M., and Bonasoni, P.: Seasonal variation of ozone and black carbon observed at Paknajol, an urban site in the Kathmandu Valley, Nepal, Atmos. Chem. Phys., 15, 1395713971, doi:10.5194/acp-15-13957-2015, 2015.

Ramana, M. V., Ramanathan, V., Podgorny, I. A., Pradhan, B. B., and Shrestha, B.: The direct observations of large aerosol radiative forcing in the Himalayan region, Geophys. Res. Lett., 31, L05111, doi:10.1029/2003g1018824, 2004.

Rappenglück, B., Schmitz, R., Bauerfeind, M., Cereceda-Balic, F., von Baer, D., Jorquera, H., Silva, Y., and Oyola, P.: An urban photochemistry study in Santiago de Chile, Atmos. Environ., 39, 2913-2931, doi:10.1016/j.atmosenv.2004.12.049, 2005.

Raut, A. K.: Brick Kilns in Kathmandu Valley: Current status, environmental impacts and future options, Himal. J. Sci., 1, 59-61, doi:10.3126/hjs.v1i1.189, 2003.

Regmi, R. P., Kitada, T., and Kurata, G.: Numerical simulation of late wintertime local flows in Kathmandu Valley, Nepal: implication for air pollution transport, J. Appl. Meteorol., 42, 389403, doi:10.1175/1520-0450(2003)042<0389:nsolwl>2.0.CO;2, 2003.

Roberts, J. M., Veres, P. R., Cochran, A. K., Warneke, C., Burling, I. R., Yokelson, R. J., Lerner, B., Gilman, J. B., Kuster, W. C., Fall, R., and de Gouw, J.: Isocyanic acid in the atmosphere and its possible link to smoke-related health effects, P. Natl. Acad. Sci. USA, 108, 8966-8971, doi:10.1073/pnas.1103352108, 2011.

Roberts, J. M., Veres, P., VandenBoer, T. C., Warneke, C., Graus, M., Williams, E. J., Lefer, B. L., Brock, C. A., Bahreini, R., Öztürk, F., Middlebrook, A. M., Wagner, N. L., Dubè, W. P. A., and de Gouw, J. A.: New insights into atmospheric sources and sinks of isocyanic acid, HNCO, from recent urban and regional observations, J. Geophys. Res.-Atmos., 119, 1060-1072, doi:10.1002/2013JD019931, 2014.

Ropkins, K. and Carslaw, D. C.: Openair - Data Analysis Tools for the Air Quality Community, The R Journal, 4, 20-29, 2012.

Rupakheti, M., Panday, A. K., Lawrence, M. G., Kim, S. W., Sinha, V., Kang, S. C., Naja, M., Park, J. S., Hoor, P., Holben, B., Sharma, R. K., Mues, A., Mahata, K. S., Bhardwaj, P., Sarkar, C., Rupakheti, D., Regmi, R. P., and Gustafsson, Ö.: Air pollution in the Himalayan foothills: overview of the SusKat-ABC international air pollution measurement campaign in Nepal, Atmos. Chem. Phys. Discuss., in preparation, 2016.

Ruuskanen, T. M., Müller, M., Schnitzhofer, R., Karl, T., Graus, M., Bamberger, I., Hörtnagl, L., Brilli, F., Wohlfahrt, G., and Hansel, A.: Eddy covariance VOC emission and deposition fluxes above grassland using PTR-TOF, Atmos. Chem. Phys., 11, 611-625, doi:10.5194/acp-11-611-2011, 2011.

Sarkar, C., Kumar, V., and Sinha, V.: Massive emissions of carcinogenic benzenoids from paddy residue burning in North India, Curr. Sci. India, 104, 1703-1709, 2013.

Sarkar, C., Sinha, V., Rupakheti, M., Panday, A. K., Bhave, P., Sinha, B., and Lawrence, M. G.: Source apportionment of VOCs in the Kathmandu Valley during the SusKat-ABC international field campaign using positive matrix factorization, Atmos. Chem. Phys. Discuss., in preparation, 2016. 
Sasaki, J., Aschmann, S. M., Kwok, E. S. C., Atkinson, R., and Arey, J.: Products of the gas-phase $\mathrm{OH}$ and $\mathrm{NO}_{3}$ radical-initiated reactions of naphthalene, Environ. Sci. Technol., 31, 3173-3179, doi:10.1021/es9701523, 1997.

Schmitz, R.: Modelling of air pollution dispersion in Santiago de Chile, Atmos. Environ., 39, 2035-2047, doi:10.1016/j.atmosenv.2004.12.033, 2005.

Seco, R., Peñuelas, J., Filella, I., Llusià, J., Molowny-Horas, R., Schallhart, S., Metzger, A., Müller, M., and Hansel, A.: Contrasting winter and summer VOC mixing ratios at a forest site in the Western Mediterranean Basin: the effect of local biogenic emissions, Atmos. Chem. Phys., 11, 13161-13179, doi:10.5194/acp11-13161-2011, 2011.

Sekimoto, K., Inomata, S., Tanimoto, H., Fushimi, A., Fujitani, Y., Sato, K., and Yamada, H.: Characterization of nitromethane emission from automotive exhaust, Atmos. Environ., 81, 523531, doi:10.1016/j.atmosenv.2013.09.031, 2013.

Sharma, R. K., Bhattarai, B. K., Sapkota, B. K., Gewali, M. B., and Kjeldstad, B.: Black carbon aerosols variation in Kathmandu Valley, Nepal, Atmos. Environ., 63, 282-288, doi:10.1016/j.atmosenv.2012.09.023, 2012.

Sharma, U. K., Kajii, Y., and Akimoto, H.: Characterization of NMHCs in downtown urban center Kathmandu and rural site Nagarkot in Nepal, Atmos. Environ., 34, 3297-3307, doi:10.1016/S1352-2310(99)00485-9, 2000.

Simon, V., Dumergues, L., Bouchou, P., Torres, L., and Lopez, A.: Isoprene emission rates and fluxes measured above a Mediterranean oak (Quercus pubescens) forest, Atmos. Res., 74, 49-63, doi:10.1016/j.atmosres.2004.04.005, 2005.

Singh, H. B., Kanakidou, M., Crutzen, P. J., and Jacob, D. J.: High concentrations and photochemical fate of oxygenated hydrocarbons in the global troposphere, Nature, 378, 50-54, 1995.

Sinha, V., Williams, J., Meyerhöfer, M., Riebesell, U., Paulino, A. I., and Larsen, A.: Air-sea fluxes of methanol, acetone, acetaldehyde, isoprene and DMS from a Norwegian fjord following a phytoplankton bloom in a mesocosm experiment, Atmos. Chem. Phys., 7, 739-755, doi:10.5194/acp-7-739-2007, 2007.

Sinha, V., Williams, J., Lelieveld, J., Ruuskanen, T. M., Kajos, M. K., Patokoski, J., Hellen, H., Hakola, H., Mogensen, D., Boy, M., Rinne, J., and Kulmala, M.: OH Reactivity Measurements within a Boreal Forest: Evidence for Unknown Reactive Emissions, Environ. Sci. Technol., 44, 6614-6620, doi:10.1021/es101780b, 2010.

Sinha, V., Custer, T. G., Klüpfel, T., and Williams, J. The effect of relative humidity on the detection of pyrrole by PTR-MS for OH reactivity measurements, Int. J. Mass Spectrom., 282, 108-111, doi:10.1016/j.ijms.2009.02.019, 2009.

Sinha, V., Williams, J., Diesch, J. M., Drewnick, F., Martinez, M., Harder, H., Regelin, E., Kubistin, D., Bozem, H., HosaynaliBeygi, Z., Fischer, H., Andrés-Hernández, M. D., Kartal, D., Adame, J. A., and Lelieveld, J.: Constraints on instantaneous ozone production rates and regimes during DOMINO derived using in-situ $\mathrm{OH}$ reactivity measurements, Atmos. Chem. Phys., 12, 7269-7283, doi:10.5194/acp-12-7269-2012, 2012.

Sinha, V., Kumar, V., and Sarkar, C.: Chemical composition of premonsoon air in the Indo-Gangetic Plain measured using a new air quality facility and PTR-MS: high surface ozone and strong influence of biomass burning, Atmos. Chem. Phys., 14, 59215941, doi:10.5194/acp-14-5921-2014, 2014.

Sommariva, R., de Gouw, J. A., Trainer, M., Atlas, E., Goldan, P. D., Kuster, W. C., Warneke, C., and Fehsenfeld, F. C.: Emissions and photochemistry of oxygenated VOCs in urban plumes in the Northeastern United States, Atmos. Chem. Phys., 11, 70817096, doi:10.5194/acp-11-7081-2011, 2011.

Staehelin, J., Keller, C., Stahel, W., Schläpfer, K., and Wunderli, S.: Emission factors from road traffic from a tunnel study (Gubrist tunnel, Switzerland). Part III: Results of organic compounds, $\mathrm{SO}_{2}$ and speciation of organic exhaust emission, Atmos. Environ., 32, 999-1009, doi:10.1016/S1352-2310(97)00339-7, 1998.

Stemmler, K., Bugmann, S., Buchmann, B., Reimann, S., and Staehelin, J.: Large decrease of VOC emissions of Switzerland's car fleet during the past decade: results from a highway tunnel study, Atmos. Environ., 39, 1009-1018, doi:10.1016/j.atmosenv.2004.10.010, 2005.

Stockwell, C. E., Veres, P. R., Williams, J., and Yokelson, R. J.: Characterization of biomass burning emissions from cooking fires, peat, crop residue, and other fuels with high-resolution proton-transfer-reaction time-of-flight mass spectrometry, Atmos. Chem. Phys., 15, 845-865, doi:10.5194/acp-15-845-2015, 2015.

Stone, E. A., Schauer, J. J., Pradhan, B. B., Dangol, P. M., Habib, G., Venkataraman, C., and Ramanathan, V.: Characterization of emissions from South Asian biofuels and application to source apportionment of carbonaceous aerosol in the Himalayas, J. Geophys. Res.-Atmos., 115, D06301, doi:10.1029/2009jd011881, 2010.

Tani, A., Hayward, S., Hansel, A., and Hewitt, C. N.: Effect of water vapour pressure on monoterpene measurements using proton transfer reaction-mass spectrometry (PTR-MS), Int. J. Mass Spectrom., 239, 161-169, doi:10.1016/j.ijms.2004.07.020, 2004.

Taylor, W. D., Allston, T. D., Moscato, M. J., Fazekas, G. B., Kozlowski, R., and Takacs, G. A.: Atmospheric photodissociation lifetimes for nitromethane, methyl nitrite, and methyl nitrate, Int. J. Chem. Kinet., 12, 231-240, doi:10.1002/kin.550120404, 1980.

Tsai, S. M., Zhang, J., Smith, K. R., Ma, Y., Rasmussen, R. A., and Khalil, M. A. K.: Characterization of non-methane hydrocarbons emitted from various cookstoves used in China, Environ. Sci. Technol., 37, 2869-2877, doi:10.1021/es026232a, 2003.

Wang, Z., Nicholls, S. J., Rodriguez, E. R., Kummu, O., Hórkko, S., Barnard, J., Reynolds, W. F., Topol, E. J., DiDonato, J. A., and Hazen, S. L.: Protein carbamylation links infammation,smoking, uremia, and atherogenesis, Nat. Med., 13, 1176-1184, 2007

Warneck, P. and Williams, J.: The Atmospheric Chemist's Companion: Numerical Data for use in the Atmospheric Sciences, Springer, Dordrecht, Heidelberg, London, New York, 1, 1-436, doi:10.1007/978-94-007-2275-0, 2012.

Warneke, C., Roberts, J. M., Veres, P., Gilman, J., Kuster, W. C., Burling, I., Yokelson, R., and de Gouw, J. A.: VOC identification and inter-comparison from laboratory biomass burning using PTR-MS and PIT-MS, Int. J. Mass Spectrom., 303, 6-14, doi:10.1016/j.ijms.2010.12.002, 2011.

Wentzell, J. J. B., Liggio, J., Li, S. M., Vlasenko, A., Staebler, R., Lu, G., Poitras, M. J., Chan, T., and Brook, J. R.: Measurements of gas phase acids in diesel exhaust: a relevant source of HNCO?, Environ. Sci. Technol., 47, 7663-7671, doi:10.1021/es401127j, 2013. 
WHO Guidelines for Indoor Air Quality: Selected Pollutants, edited by: Theakston, F., World Health Organization: WHO Regional Office for Europe, Copenhagen, Denmark, 1-454, 2010.

Yassaa, N., Meklati, B. Y., Brancaleoni, E., Frattoni, M., and Ciccioli, P.: Polar and non-polar volatile organic compounds (VOCs) in urban Algiers and saharian sites of Algeria, Atmos. Environ., 35, 787-801, doi:10.1016/S1352-2310(00)00238-7, 2001.

Yokelson, R. J., Burling, I. R., Gilman, J. B., Warneke, C., Stockwell, C. E., de Gouw, J., Akagi, S. K., Urbanski, S. P., Veres, P., Roberts, J. M., Kuster, W. C., Reardon, J., Griffith, D. W. T., Johnson, T. J., Hosseini, S., Miller, J. W., Cocker III, D. R., Jung, H., and Weise, D. R.: Coupling field and laboratory measurements to estimate the emission factors of identified and unidentified trace gases for prescribed fires, Atmos. Chem. Phys., 13, 89-116, doi:10.5194/acp-13-89-2013, 2013.

Yoshino, A., Nakashima, Y., Miyazaki, K., Kato, S., Suthawaree, J., Shimo, N., Matsunaga, S., Chatani, S., Apel, E., Greenberg, J., Guenther, A., Ueno, H., Sasaki, H., Hoshi, J. Y., Yokota, H., Ishii, K., and Kajii, Y.: Air quality diagnosis from comprehensive observations of total $\mathrm{OH}$ reactivity and reactive trace species in urban central Tokyo, Atmos. Environ., 49, 51-59, doi:10.1016/j.atmosenv.2011.12.029, 2012.

Young, P. J., Emmons, L. K., Roberts, J. M., Lamarque, J. F., Wiedinmyer, C., Veres, P., and VandenBoer, T. C.: Isocyanic acid in a global chemistry transport model: tropospheric distribution, budget, and identification of regions with potential health impacts, J. Geophys. Res.-Atmos., 117, D10308, doi:10.1029/2011jd017393, 2012.
Yu, Y., Panday, A., Hodson, E., Galle, B., and Prinn, R.: Monocyclic aromatic hydrocarbons in Kathmandu during the winter season, Water Air Soil Poll., 191, 71-81, doi:10.1007/s11270-007-96076, 2008

Yu, Y., Galle, B., Panday, A., Hodson, E., Prinn, R., and Wang, S.: Observations of high rates of $\mathrm{NO}_{2}-\mathrm{HONO}$ conversion in the nocturnal atmospheric boundary layer in Kathmandu, Nepal, Atmos. Chem. Phys., 9, 6401-6415, doi:10.5194/acp-9-6401-2009, 2009.

Zhang, Z., Lin, L., and Wang, L.: Atmospheric oxidation mechanism of naphthalene initiated by $\mathrm{OH}$ radical. A theoretical study, Phys. Chem. Chem. Phys., 14, 2645-2650, doi:10.1039/c2cp23271e, 2012.

Zhao, R., Lee, A. K. Y., Wentzell, J. J. B., McDonald, A. M., ToomSauntry, D., Leaitch, W. R., Modini, R. L., Corrigan, A. L., Russell, L. M., Noone, K. J., Schroder, J. C., Bertram, A. K., Hawkins, L. N., Abbatt, J. P. D., and Liggio, J.: Cloud partitioning of isocyanic acid (HNCO) and evidence of secondary source of HNCO in ambient air, Geophys. Res. Lett., 41, 6962-6969, doi:10.1002/2014g1061112, 2014. 